\title{
Dopamin, NADH ve Askorbik Asitin Elektroyükseltgenmesine Elektrokimyasal Olarak İndirgenmiş Grafen Oksit, Politiyonin ve Altın Nanopartiküllerin Etkisi
}

\section{Effect of Electrochemically Reduced Graphene Oxide, Polythionine and Gold Nanoparticles on Electrooxidation of Dopamine, NADH and Ascorbic Acid}

\author{
Melike Bilgi Kamaç ${ }^{1 *}$, Muhammed Altun², Merve Yılmaz ${ }^{3}$ \\ Geliş / Received: 05/11/2020 \\ Revize / Revised: 17/01/2021 \\ Kabul / Accepted: 17/01/2021
}

\begin{abstract}
ÖZ
Bu çalışmada, yüzey baskılı karbon elektrotlar (SPCE) elektrokimyasal olarak indirgenmiş grafen oksit (ERGO) ile modifiye edilmiş (SPCE/ERGO), ardından elektropolimerizasyon tekniği ile politiyonin (PTH) filmi SPCE/ERGO'lar üzerinde oluşturulmuştur (SPCE/ERGO/PTH). PTH'nin SPCE/ERGO'lar üzerindeki elektropolimerizasyonu için optimum döngü sayısı belirlenmiş̧ir. SPCE/ERGO/PTH elektrotları üzerinde elektrodepozisyon metodu ile altın nanopartiküller (AuNP) oluşturulmuş ve elde edilen SPCE/ERGO/PTH/AuNP elektrotlarının elektrokimyasal karakterizasyonları dönüşümlü voltametri (CV) ile yapılmıştır. Dopamin (DA), nikotinamid adenin dinükleotitin indirgenmiş formu (NADH) ve askorbik asitin (AA) elektroyükseltgenmesine ERGO, PTH ve AuNP'nin elektrokatalitik etkileri incelenmiş ve PTH'nin üç analit için de medyatör olarak rol oynadığı gözlenmiştir. ERGO, PTH ve AuNP'nin birlikte gösterdikleri sinerjik etki ile DA, NADH ve AA'nın anodik pik potansiyelleri negatif yöne kaymış ve anodik pik akımları artmıştır. DA, NADH ve AA'nın difüzyon katsayıları (D) sirasiyla $3.37 \times 10^{-8}, 7.79 \times 10^{-9}$ ve $1.51 \times 10^{-8}$ olarak, elektron transfer katsayıları $(\alpha)$ ise sirasiyla 0.327, 0.701 ve 0.373 olarak hesaplanmıştır. pH'nın DA, NADH ve AA'nın elektroyükseltgenmesine etkisi de incelenmiş ve $\mathrm{pH}$ arttıkça her üç analit için de anodik pik potansiyellerinin azaldığı gözlenmiştir.
\end{abstract}

Anahtar Kelimeler-Dopamin, NADH, Askorbik Asit, Elektroyükseltgenme

\begin{abstract}
In this study, screen-printed carbon electrodes (SPCE) were modified with electrochemically reduced graphene oxide (ERGO) (SPCE/ERGO), then polythionine (PTH) film was formed on SPCE/ERGO by electropolymerization technique (SPCE/ERGO/PTH). The optimum number of cycles has been determined for the electropolymerization of PTH on SPCE/ERGO. Gold nanoparticles (AuNP) were formed on SPCE/ERGO/PTH electrodes by electrodeposition method and electrochemical characterizations of SPCE/ERGO/PTH/AuNP electrodes were made by cyclic voltammetry (CV). The electrocatalytic effects of ERGO, PTH and AuNP on the
\end{abstract}

\footnotetext{
1*Sorumlu yazar iletișim: melikebilgikamac@gmail.com (https://orcid.org/0000-0002-3381-7522)

Tıbbi Laboratuvar Teknikleri Programı, Çankırı Karatekin Üniversitesi, Çankırı

2İletişim: maltun@gmail.com (https://orcid.org/0000-0002-0387-1819)

Tıbbi Laboratuvar Teknikleri Programı, Çankırı Karatekin Üniversitesi, Çankırı

3̇letişim: mrve0891@gmail.com (https://orcid.org/0000-0003-3690-2455)

Kimya Bölümü, Çankırı Karatekin Üniversitesi, Çankırı
} 
electrooxidation of dopamine (DA), nicotinamide adenine dinucleotide (NADH) and ascorbic acid (AA) were investigated, and PTH was observed to play a role as a mediator for three analytes. The anodic peak potentials of DA, NADH and AA shifted in the negative direction, and anodic peak currents increased due to the synergistic effect of ERGO, PTH and AuNP together. The diffusion coefficients (D) of DA, NADH and AA were calculated as $3.37 \times 10^{-8}, 7.79 \times 10^{-9}$ and $1.51 \times 10^{-8}$, respectively, and also the electron transfer coefficients $(\alpha)$ were calculated as $0.327,0.701$ and 0.373 , respectively. The effect of $\mathrm{pH}$ on the electrooxidation of DA, NADH and AA was also examined, and it was observed that the anodic peak potentials for all three analytes decreased with increasing the $\mathrm{pH}$.

\section{Keywords- Dopamine, NADH, Ascorbic Acid, Electrooxidation}

\section{GIRIŞ}

Dopamin (DA), katekolamin sınıfı içinde en önemli moleküldür ve beyin sisteminde önemli bir rol oynar. Merkezi sinir, renal, hormonal ve kardiyovasküler sistemlerin işlevlerinden sorumludur [1-2]. Anormal DA seviyeleri, şizofreni, Huntington hastalığı, Parkinson hastalığı ve demans gibi çeşitli hastalıklara neden olabilir [35]. Nikotinamid adenin dinükleotidin indirgenmiş formu (NADH), insan vücudunda bulunan en önemli koenzimdir. 300'den fazla dehidrojenaz enzimi, organizmaların metabolizmasında rol oynayan bir koenzim olarak NADH'nin yükseltgenmiş formunu $\left(\mathrm{NAD}^{+}\right)$kullanır [6-7]. NADH, dopamin, noradrenalin ve serotonin gibi nörotransmitterlerin hücresel üretimini uyarır. Vücuttaki NADH eksikliği, ATP üretiminin olmaması nedeniyle hücresel düzeyde bir enerji boşluğuna neden olur. Beyindeki ATP miktarı azalırsa dikkat eksikliği ve Alzheimer demansı gibi olumsuz etkilere neden olabilir. Hücredeki aşırı NADH seviyeleri, aşırı enerji üretimi nedeniyle uykusuzluk, kaygı, yorgunluk ve aşırı uyarılma gibi kötü durumlara da yol açabilir [8-9]. Askorbik asit (AA) olarak da bilinen $C$ vitamini, biyolojik sistemler için gerekli olan en önemli suda çözünür lakton moleküllerinden biridir, meyve ve sebzeler gibi birçok bitki materyalinde bulunur. Bitkiler ve birçok memeli tarafından sentezlenebilir, ancak insanlar tarafindan sentezlenemez. Kolajen oluşumunda anahtar rol oynar, iyi bir antioksidan görevi görür ve doku hasarını önler [10-11]. Diyette AA eksikliği çeşitli hastalıklara, diş etlerinin şişmesine, gevşek dişlere ve kemik deformasyonuna neden olur [12]. İskorbüt, anemi, soğuk algınlığ ve kısırlığın tedavisinde kullanılır. İyi antioksidan aktivitesi nedeniyle birçok gıda maddesinde renk, tat ve koku değişikliklerinden korumak için kullanılmaktadır [13]. DA, NADH ve AA'nın elektrokimyasal tayini için birçok sensör geliştirilmiştir [14-16]. Bu analitlerin elektrokimyasal tayini için ilk olarak elektroyükseltgenme özellikleri incelenmelidir.

Fenazin ve fenotiyazin polimerleri, sensör ve biyosensörlerde analitin doğrudan ve/veya dolaylı belirlenmesinde redoks medyatörleri olarak sıklıkla kullanılmaktadır [17-18]. Bu polimerlerin elektrokatalitik özellikleri, birçok analitin yükseltgenme potansiyelini azaltarak sensörün duyarlılığını arttırmakta ve tayin sınırlarını düşürmektedir [19]. Tiyonin (TH), a konumunda iki amino grubu içeren katyonik bir fenotiyazin boyasıdır [20-21]. TH, diğer fenotiyazin boyaları gibi, iletken bir polimer oluşturmak için elektrokimyasal olarak polimerleştirilebilir. Son zamanlarda poli(tiyonin) (PTH), sensör ve biyosensörlerde hem iletken polimer hem de redoks medyatörü olarak kullanılan bir polimerdir [22-24]. Grafen tabakaları yüksek yüzey alanı, yüksek mekanik direnç ve mükemmel iletkenliğe sahip ultra hassas sensörlerin ve biyosensörlerin hazırlanmasında kullanılır [2526]. Grafen oksit ve indirgenmiş grafen oksit, kolay sentezlenebilirlik, suda iyi çözünebilirlik ve biyouyumluluk gibi özellikleri nedeniyle biyosensör üretimi, hücresel görüntüleme ve ilaç salımı gibi alanlarda çok çeşitli uygulamalara sahiptir [27-28]. Altın nanopartiküller (AuNP), yüksek yüzey/hacim oranına sahip olması, yüksek anodik potansiyellerde çalışma ihtiyacını ortadan kaldırması ve biyouyumlu olması gibi özellikleri nedeniyle elektrokimyasal sensör ve biyosensörlerde yaygın olarak kullanılmaktadır [29-30]. Yüzey baskılı elektrotlar (SPE) serigrafi tekniği ile üretilir. Bu elektrotlar, karmaşık numune ön işlemleri olmadan kullanılabilen sensör ve biyosensörlerin hazırlanmasında sıklıkla kullanılır [31-32]. SPE'lerin doğrudan yerinde ölçmeye imkan tanıması, tek kullanımlık olacak şekilde hızlı, pratik, düşük maliyetli olması ve hasta başı testlere uygunluk göstermesi gibi birçok avantajı vardır. SPE'lerin nanomalzemeler ve polimerlerle modifikasyonu, sensör ve biyosensörlerin geliştirilmesi için ilgi çekicidir [33-35].

Bu çalışmada, yüzey baskılı karbon elektrotlar (SPCE), ERGO, PTH ve AuNP ile modifiye edilmiş ve hazırlanan SPCE/ERGO/PTH/AuNP elektrotlarının elektrokimyasal karakterizasyonu gerçekleştirilmiştir. SPCE/ERGO/PTH/AuNP elektrotları üzerinde DA, NADH ve AA'nın elektroyükseltgenmesine ERGO, PTH ve AuNP'nin elektrokatalitik etkileri ve pH'nın etkisi incelenmiştir. DA, NADH ve AA'nın difüzyon katsayıları (D) 


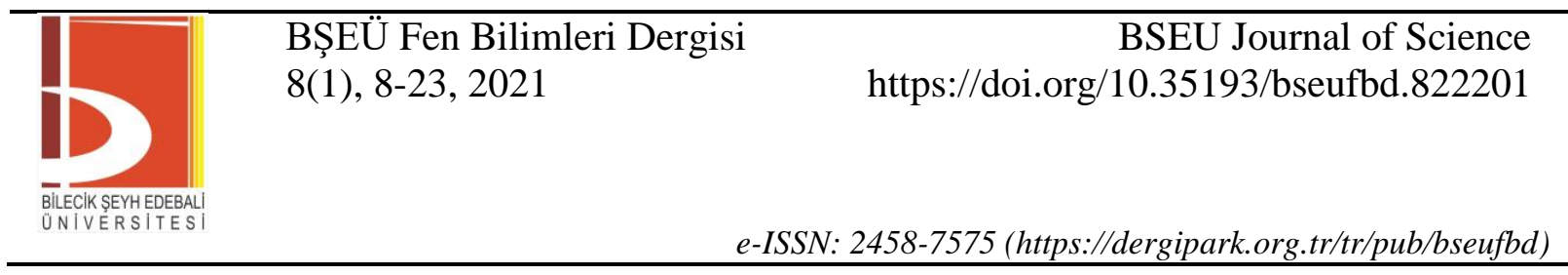

ve elektron transfer katsayıları $(\alpha)$ hesaplanmıştır. Literatürde SPCE/ERGO/PTH/AuNP elektrotları ile DA, NADH ve AA'nın elektroyükseltgenmesinin incelendiği bir çalışmaya rastlanmamıştır.

\section{MATERYAL VE YÖNTEM}

\section{A. Materyal}

Dopamin (DA), nikotinamid adenin dinükleotitin indirgenmiş formu (NADH), askorbik asit (AA), grafen oksit $(\mathrm{GO})$, tiyonin $(\mathrm{TH})$, kloroaurik asit $\left(\mathrm{HAuCl}_{4}\right)$, potasyum hekzosiyanoferrat $\left(\mathrm{K}_{3} \mathrm{Fe}(\mathrm{CN})_{6}\right)$ potasyum hekzosiyanoferrit $\left(\mathrm{K}_{4} \mathrm{Fe}(\mathrm{CN})_{6}\right)$ ve sodyum hidroksit $(\mathrm{NaOH})$ Sigma-Aldrich firmasından, potasyum klorür $(\mathrm{KCl})$, potasyum dihidrojen fosfat $\left(\mathrm{KH}_{2} \mathrm{PO}_{4}\right)$, dipotasyum hidrojen fosfat $\left(\mathrm{K}_{2} \mathrm{HPO}_{4}\right)$, asetik asit $\left(\mathrm{CH}_{3} \mathrm{COOH}\right)$, sodyum asetat $\left(\mathrm{CH}_{3} \mathrm{COONa}\right)$, dimetil formamid (DMF), hidroklorik asit ( $\mathrm{HCl}, \% 37$ 'lik) ise Merck firmasından tedarik edilmiştir. Kullanılan tüm kimyasallar yüksek analitik saflıktadır. Deneylerde Millipore Milli-Q Direct Q-3 ultra saf su cihazından elde edilen su kullanılmıştır. İstenilen pH'da tampon çözelti hazırlamak için, standart tampon çözeltilerle kalibre edilmiş Mettler Toledo pH-metre kullanılmıştır.

\section{B. Elektrokimyasal Ölçümler}

Tek kullanımlık yüzey baskılı karbon elektrotlar (SPCE) DropSens (Oveido, İspanya) firmasından temin edilmiştir. SPCE'lerin çalışma elektrotu (4 mm) ve karşıt elektrotu karbondan, referans elektrotu ise $\mathrm{Ag} / \mathrm{AgCl}$ 'den $(0.1 \mathrm{M} \mathrm{KCl}$ ) oluşmaktadır. Elektrotların potantiyostata (Dropsens $\mu$ Stat 400 Bipotentiostat/Galvanostat, Oveido, İspanya) bağlantısı DropSens'ten temin edilen konnektörler ile sağlanmıştır. Tüm elektrokimyasal ölçümler, cihazın sinyalleri DropView 8400 yazılımı ile değerlendirilen bilgisayar kontrollü Dropsens $\mu$ Stat 400 Bipotentiostat/Galvanostat ile gerçekleştirilmiştir. SPCE elektrotlarının yüzeylerinin temizlenmesi ve aktivasyonu için $50 \mathrm{mM} \mathrm{pH} 7.5$ fosfat tamponu içerisinde $+1.8 \mathrm{~V}$ 'da $300 \mathrm{~s}$ boyunca potansiyel uygulanarak elektrokimyasal ön işlem uygulanmıştır [14-15, 35]. Elektrokimyasal ölçümler ve deneyler en az 3 tekrarlı olarak gerçekleştirilmiştir.

\section{SPCE/ERGO/PTH/AuNP Elektrotunun Hazırlanmast}

1.0 mg GO ve 1.0 mL DMF: $\mathrm{H}_{2} \mathrm{O}(1: 1)$ karışımına 2 saatlik sonikatör uygulamasıyla kararlı ve homojen bir süspansiyon hazırlanmıştır. Elektrokimyasal olarak indirgenmiş grafen oksitin (ERGO) SPCE’ler yüzeyinde hazırlanması için, elektrotların yüzeyine hazırlanan GO süspansiyonundan $70 \mu \mathrm{L}$ damlatılmış ve $0.0 \mathrm{~V}$ ile $-1.5 \mathrm{~V}$ potansiyel aralığında $50 \mathrm{mV} \mathrm{s}^{-1}$ tarama hızında 15 döngü dönüşümlü voltametri uygulanmıştır (SPCE/ERGO) [36]. SPCE/ERGO'ların üzerinde PTH oluşumu için, $50 \mathrm{mM} \mathrm{pH} 7.5$ fosfat tamponunda hazırlanan $1 \mathrm{mM}$ tiyonin çözeltisine $-0.5 \mathrm{~V}$ ile $+1 \mathrm{~V}$ potansiyel aralığında $50 \mathrm{mV} \mathrm{s}^{-1}$ tarama hızında 20 döngü dönüşümlü voltametri uygulanmıştır [37]. SPCE/ERGO/PTH'lerin üzerinde AuNP'nin hazırlanması için $4 \mathrm{mM} \mathrm{HAuCl} 4$ (50 mM pH 7 fosfat tamponu, $0.1 \mathrm{M} \mathrm{KCl}$ ) çözeltisine $50 \mathrm{mV} \mathrm{s}^{-1}$ tarama hızında $-1.3 \mathrm{~V}$ ile $-0.2 \mathrm{~V}$ potansiyel aralığında 10 döngü dönüşümlü voltametri uygulanmıştır [38]. Her bir modifikasyon basamağından sonra, elektrotların yüzeyi ultra saf su ile yıkanmış ve yüksek saflıktaki argon gazı ile kurutulmuştur.

\section{BULGULAR VE TARTIŞMA}

\section{A. SPCE ve SPCE/ERGO Elektrotlart Üzerinde Tiyoninin Elektropolimerizasyonu}

PTH filminin yalın SPCE ve SPCE/ERGO üzerine biriktirilmesi, $1 \mathrm{mM}$ tiyonin içeren $50 \mathrm{mM}$ PBS (fosfat tamponu, $\mathrm{pH}=7.5$ ) çözeltisine -0.5 ile $+1.0 \mathrm{~V}$ potansiyel aralığında $50 \mathrm{mV} \mathrm{s}^{-1}$ tarama hızında 20 döngü dönüşümlü voltametri uygulanmasiyla gerçekleştirilmiştir. PTH filminin oluşumu ve büyümesi için elektrota ön anodizasyon işlemi uygulanmalıdır. Bu işlem uygulandığında elektrot yüzeyinde pozitif bir yük birikir ve tiyonin katyon radikalleri oluşur [39]. Bu çalışmada SPCE'lere $+1.8 \mathrm{~V}$ potansiyel 300 sn uygulanarak elektrot yüzeyinde pozitif yük biriktirilmiştir. Dönüşümlü voltametri ile elektrot yüzeyinde PTH filmi oluşturmak için gereken pozitif potansiyelin en az $+0.8 \mathrm{~V}$ olması gerektiği bildirilmiştir. +0.8 V'nin altındaki potansiyellerde, TH'nin löko-TH'ye sadece 2 elektronlu indirgenmesi gözlenir ve tiyonin polimerleşmez [40]. Şekil 1A ve 1B'de yalın SPCE ve SPCE/ERGO üzerinde PTH'nin elektropolimerizasyonu sırasında elde edilen dönüşümlü voltamogramlar verilmiştir. Katyon radikalinin oluşumu için gerekli olan TH monomerinin tersinmez oksidasyon piki, her iki elektrotta da yaklaşık +0.70 V'de gözlenmiştir. TH monomerinin tersinmez oksidasyon pikinin çeşitli elektrotlarda daha yüksek potansiyellerde gözlendiği rapor edilmiştir $[18,40]$ Çalışmamızda SPCE elektrotlarına elektrokimyasal ön işlemin uygulanması, PTH filminin oluşması için gerekli olan TH monomerinin tersinmez oksidasyon pik potansiyelini azaltmıştır. Tiyoninin elektropolimerizasyonu sırasında her iki elektrotta da PTH'nin redoks çifti (-0.15 V'da anodik pik potansiyeli, Epa, -0.30 V'da katodik pik potansiyeli, Epc) gözlenmiştir. Döngü 


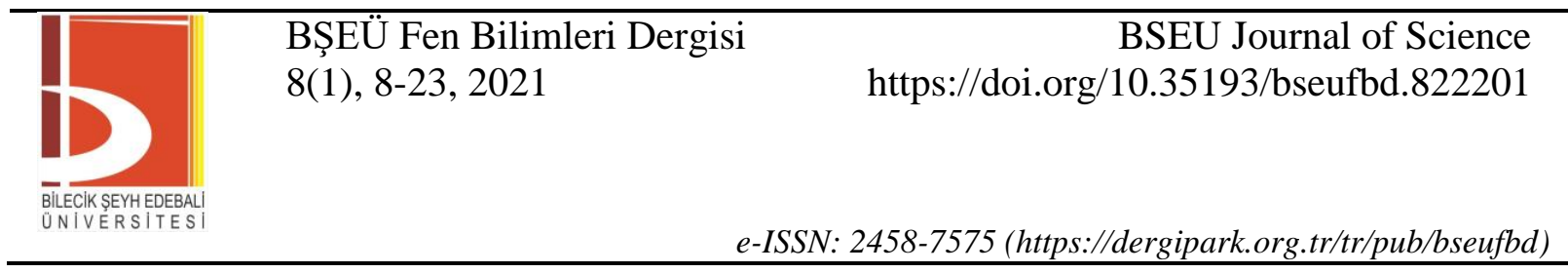

sayısı arttıkça anodik ve katodik pik akımları da artmış ve polimer filmi büyümüştür. Elde edilen sonuçlara göre elektrot yüzeyinde PTH filmi oluşturulmuştur [22, 41]. Politiyoninin pik akımlarındaki bu artış yalın SPCE'ye göre SPCE/ERGO'da daha fazladır. Tiyoninin elektropolimerizasyonu için SPCE/ERGO elektrotunun daha uygun olduğu sonucuna varılabilir. Bu durum, indirgenmiş grafen oksidin mükemmel elektronik özelliklerine ve elektrotun elektroaktif yüzey alanını artırmasına bağlanabilir. Bu sonuçlar, çok duvarlı karbon nanotüpler (MWCNT) ile modifiyeli elektrotlar üzerinde PTH'nin hazırlanması ile benzerdir [42-43].
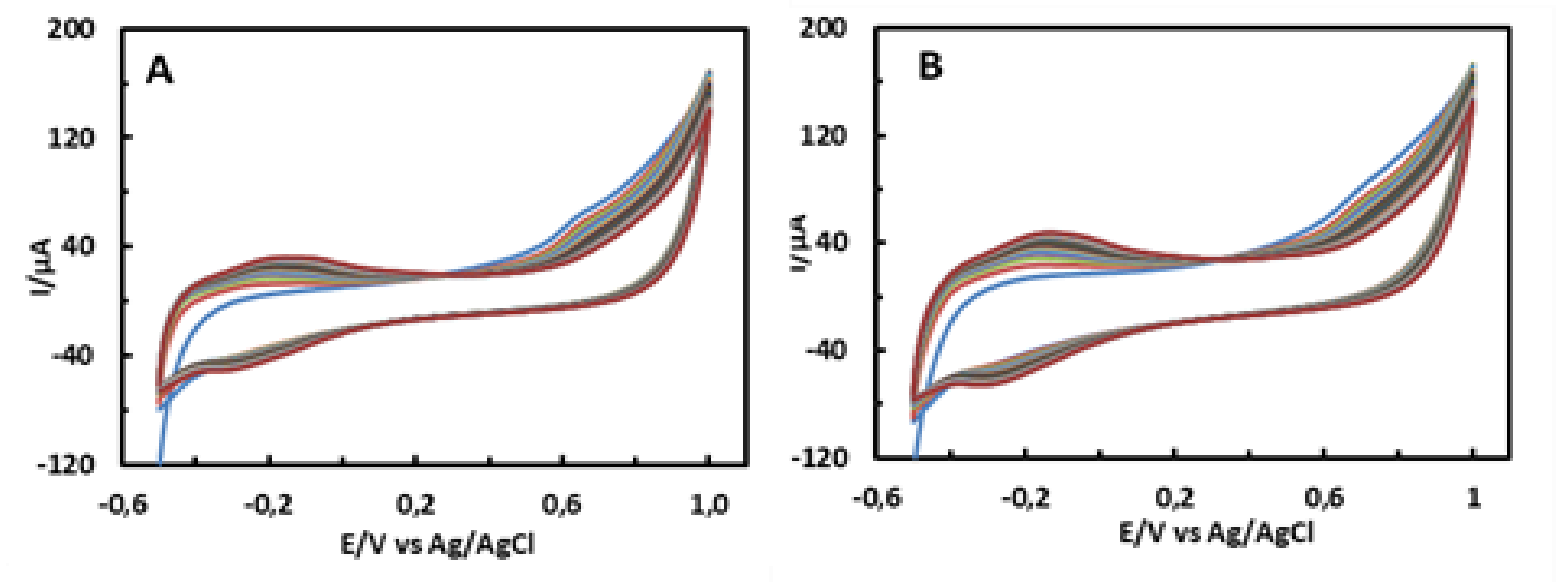

Şekil 1. $1 \mathrm{mM}$ TH'nin SPCE ve SPCE/ERGO üzerindeki elektropolimerizasyonu sırasında elde edilen dönüşümlü voltamogramlar (potansiyel aralı̆̆: $-0.5 \mathrm{~V}$ ve $+1.0 \mathrm{~V}$; tarama hızı: $50 \mathrm{mV} \mathrm{s}^{-1}, 20$ döngü, $50 \mathrm{mM} \mathrm{pH} 7.5 \mathrm{PBS}$ )
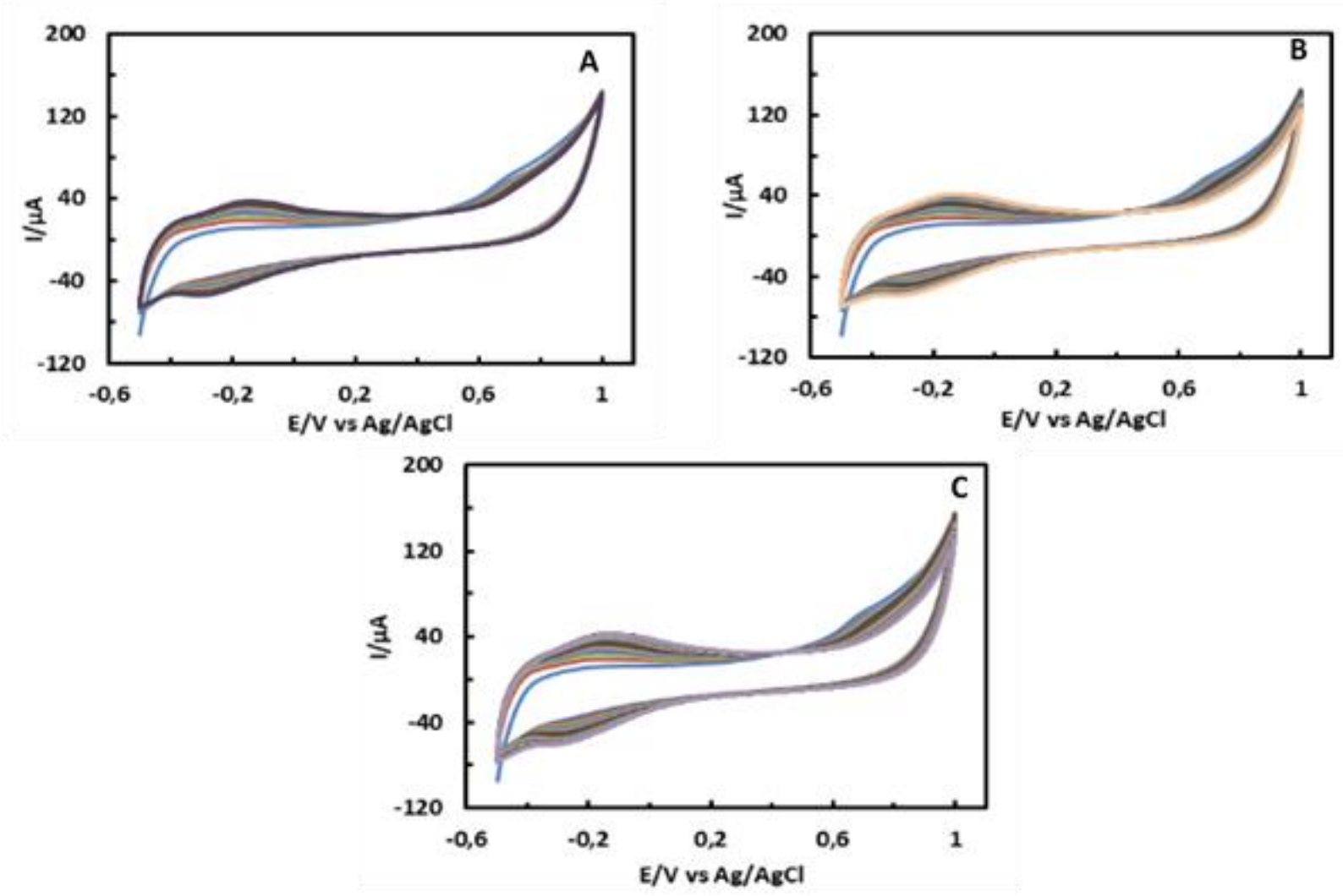

Şekil 2. 1 mM TH'nin SPCE/ERGO üzerindeki elektropolimerizasyonu sırasında elde edilen dönüşümlü voltamogramlar A: 10 döngü; B: 30 döngü; C: 40 döngü (potansiyel aralığı: $-0.5 \mathrm{~V} \mathrm{ve}+1.0 \mathrm{~V}$; tarama hızı: $50 \mathrm{mV} \mathrm{s}^{-1}, 50 \mathrm{mM} \mathrm{pH} 7.5 \mathrm{PBS}$ ) 


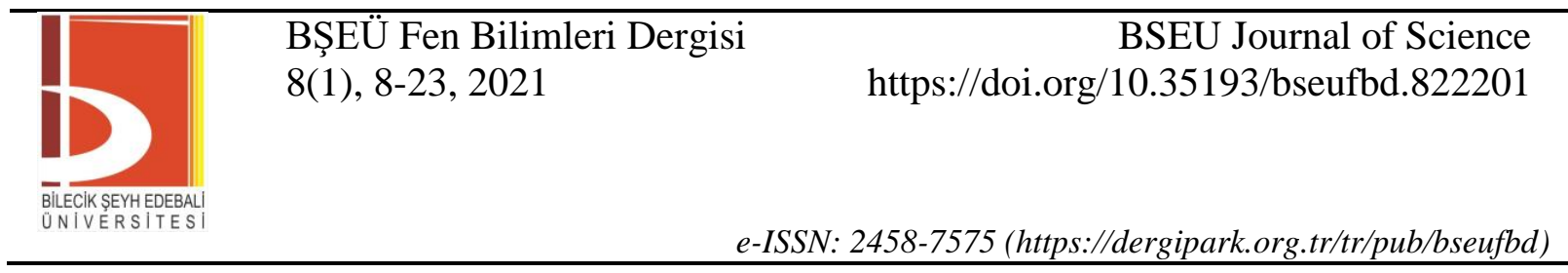

TH'nin dönüşümlü voltametri tekniği ile polimerizasyonunda, döngü sayısının optimizasyonu çok önemlidir. Döngü sayısı az olduğunda, polimerin elektrot yüzeyindeki film kalınlı̆̆ çok ince olur ve beklenen etki gözlenemez. Fazla sayıda döngü uygulandığında ise elektrot yüzeyinde kalın bir film oluşur ve film boyunca difüzyon azalır. Bu durumda sensör ve biyosensörlerin hassasiyeti azalır [34, 44-45]. PTH filminin oluşumundaki döngü sayısını optimize etmek için, farklı döngü sayılarında (10, 20, 30 ve 40) SPCE/ERGO üzerinde TH'nin elektropolimerizasyonu gerçekleştirilmiştir. Elektropolimerizasyon sırasında elde edilen dönüşümlü voltamogramlar 20 döngü için Şekil 1B'de, 10, 30 ve 40 döngü için ise sırasıyla Şekil 2A, 2B ve 2C'de verilmiştir. Anodik ve katodik pik akımlarının döngü sayısının artışı ile arttığı, polimerin her döngüde dallanıp büyüdüğü ve elektrot yüzeyine kaplandığı voltamogramlardan anlaşılmaktadır. Şekil 3 'te farklı döngü sayılarında hazırlanmış SPCE/ERGO/PTH elektrotlarının fosfat tamponu çözeltisinde elde edilen dönüşümlü voltamogramları verilmiştir. Döngü sayısı 10'dan 20'ye arttıkça anodik ve katodik pik akımları artarken, 20'den 40'a arttıkça pik akımlarında fazla bir değişimin olmadığı gözlenmiştir. Elektrot yüzeyindeki polimerin film kalınlığının döngü sayısı artışı ile giderek artması, elektronların elektrot yüzeyine difüzyonunu azaltmıştır.

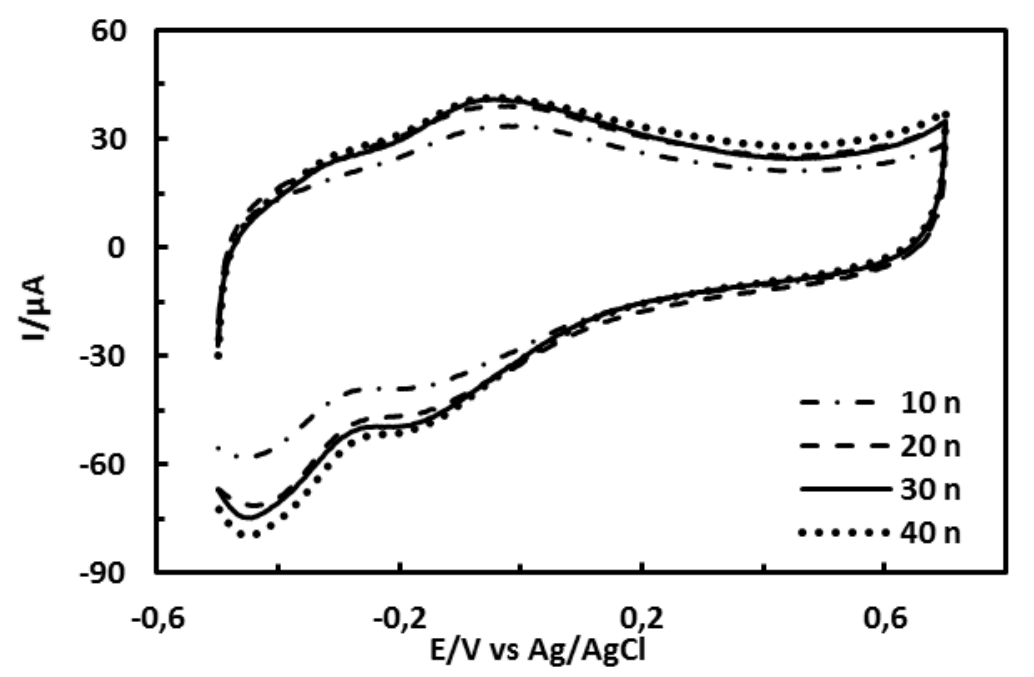

Şekil 3. Farklı döngü sayılarında hazırlanan SPCE/ERGO/PTH elektrotlarının tampon çözeltide $-0.5 \mathrm{~V}$ ve $+0.7 \mathrm{~V}$ potansiyel aralığında elde edilen dönüşümlü voltamogramları (döngü sayıları: 10, 20, 30, 40; tarama hızı: $50 \mathrm{mV} \mathrm{s}^{-1} ; 50 \mathrm{mM} \mathrm{pH} \mathrm{7.0} \mathrm{PBS,} \mathrm{0,1} \mathrm{M} \mathrm{KCl)}$

PTH'nin elektroaktif bölgelerinin ortalama yüzey konsantrasyonlarını hesaplamak için, farklı döngü sayılarında hazırlanan SPCE/ERGO/PTH elektrotlarının $50 \mathrm{mM} \mathrm{pH} 7.0$ fosfat tamponu çözeltisinde farklı tarama hızlarında $\left(10,25,50,75,100\right.$ ve $\left.125 \mathrm{mV} \mathrm{s}^{-1}\right)$ dönüşümlü voltamogramları alınmıştır. 10, 20, 30 ve 40 döngü sayılarında hazırlanan SPCE/ERGO/PTH elektrotları için elde edilen voltamogramlar sırasıyla Şekil 4A, 4B, 4C ve 4D'de verilmiştir. Anodik ve katodik pik akımlarının, tarama hızı ile doğrusal olarak arttığı (Şekil 4, iç grafikler) ve elektrokimyasal kinetiğin yüzey kontrollü proses olduğu görülmektedir. Yüzey kontrollü elektrokimyasal proses için SPCE/ERGO elektrotlarının yüzeyindeki PTH'nin elektroaktif bölgelerinin ortalama yüzey konsantrasyonu $(\Gamma)$, aşağıdaki denklem kullanılarak hesaplanmıştır [46]:

$$
\mathrm{Ip}=\mathrm{n}^{2} \mathrm{~F}^{2} v \mathrm{~A} \Gamma / 4 \mathrm{R} \mathrm{T}
$$

Burada $i_{p}$ pik akımını, A elektroaktif yüzey alanını $\left(0.205 \mathrm{~cm}^{2}\right.$, [14]), $\mathrm{n}$ transfer edilen elektronların sayısını, $v$ potansiyel tarama hızını $\left(\mathrm{V} \mathrm{s}^{-1}\right), \mathrm{T}$ sıcaklığ $(293.15 \mathrm{~K}), \mathrm{R}$ gaz sabitini $\left(8,314 \mathrm{~J} \mathrm{~K}^{-1} \mathrm{~mol}^{-1}\right)$ ve $\mathrm{F}$ ise Faraday sabitini ( $96485 \mathrm{C} \mathrm{mol}^{-1}$ ) ifade eder. 10, 20, 30 ve 40 döngü sayılarında PTH modifiyeli SPCE/ERGO'lar için $\Gamma$ değerleri sırasıyla $3.85 \times 10^{-10}, 4.53 \times 10^{-10}, 4.11 \times 10^{-10}$ ve $3.71 \times 10^{-10} \mathrm{~mol} \mathrm{~cm}^{-2}$ olarak hesaplanmıştır. En yüksek yüzey konsantrasyonu 20 döngü ile hazırlanmış SPCE/ERGO/PTH elektrotunda elde edildiği için optimum döngü sayısı 20 olarak belirlenmiştir. 


\begin{tabular}{|c|c|c|}
\hline & $\begin{array}{l}\text { BŞEÜ Fen Bilimleri Dergisi } \\
8(1), 8-23,2021\end{array}$ & $\begin{array}{r}\text { BSEU Journal of Science } \\
\text { https://doi.org/10.35193/bseufbd.822201 }\end{array}$ \\
\hline & & 2458-7575 (https://dergipark.org.tr/tr/pub/bseufbd) \\
\hline
\end{tabular}
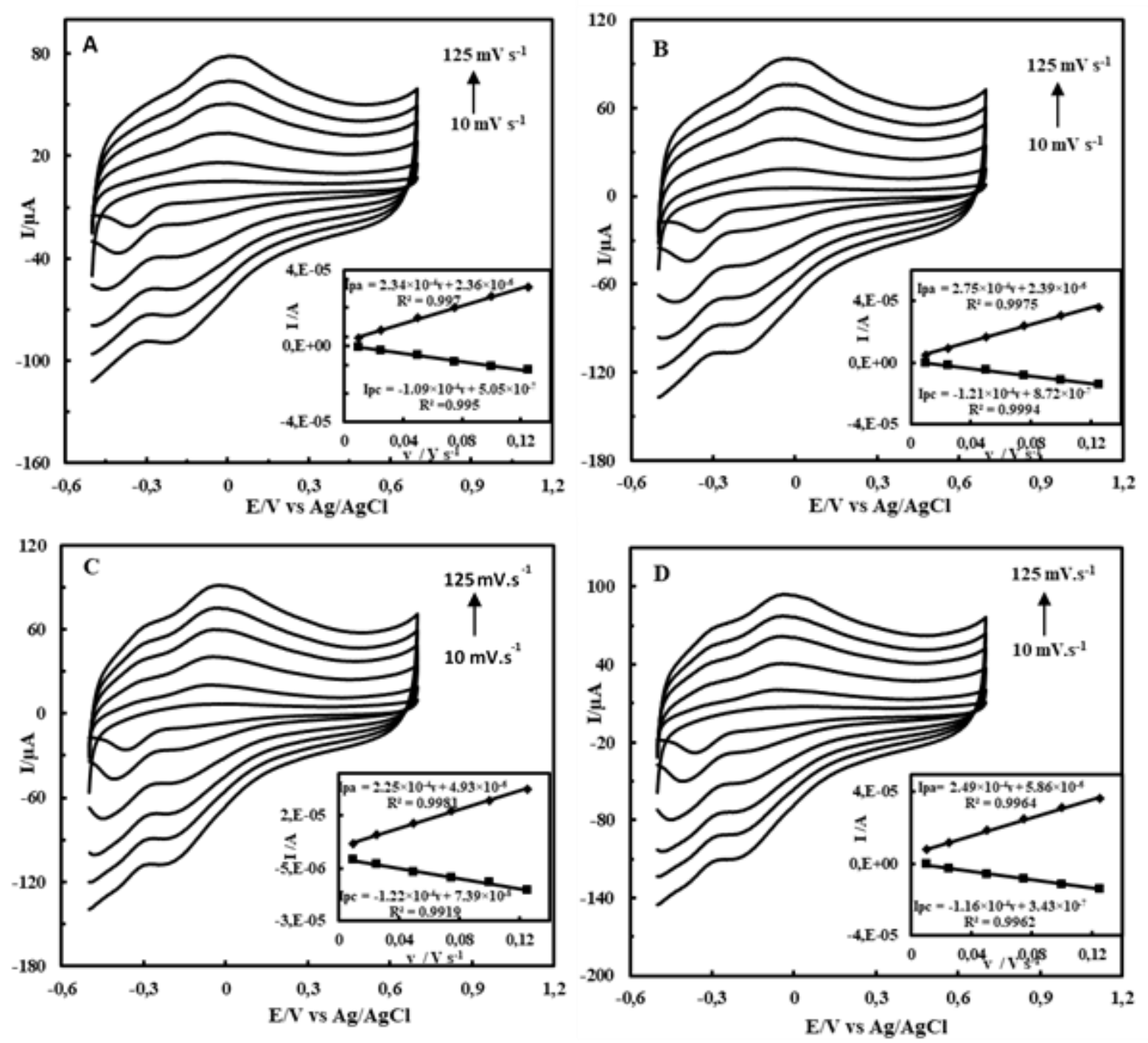

Şekil 4. Farklı döngü sayılarında hazırlanan SPCE/ERGO/PTH elektrotlarının tampon çözeltide farklı tarama hızlarında elde edilen dönüşümlü voltamogramları A: 10 döngü; B: 20 döngü; C: 30 döngü; C: 40 döngü (potansiyel aralığı: $-0.5 \mathrm{~V}$ ve $+0.7 \mathrm{~V}$; tarama hızları: 10, 25, 50, 75, 100 ve $125 \mathrm{mV} \mathrm{s}^{-1} ; 50 \mathrm{mM} \mathrm{pH} 7.0$ PBS, 0,1 M KCl). İç grafikler: dönüşümlü voltamogramlardan elde edilen pik akımları-tarama hızı grafikleri

\section{B. SPCE/ERGO/PTH/AuNP Elektrotunun Elektrokimyasal Karakterizasyonu}

Modifiye edilmiş elektrotların formülasyonunda yer alan ERGO, PTH ve AuNP'nin etkisini incelemek için SPCE, SPCE/ERGO, SPCE/ERGO/PTH ve SPCE/ERGO/PTH/AuNP elektrotlarının $5 \mathrm{mM}\left[\mathrm{Fe}(\mathrm{CN})_{6}\right]^{-3 / 4}(1$ $\mathrm{M} \mathrm{KCl)} \mathrm{çözeltisinde} \mathrm{dönüşümlü} \mathrm{voltamogramları} \mathrm{alınmış} \mathrm{ve} \mathrm{elde} \mathrm{edilen} \mathrm{voltamogramlar} \mathrm{Şekil} \mathrm{5A'da} \mathrm{verilmiştir.}$ Voltamogramlardan elde edilen anodik pik akımı (Ipa), katodik pik akımı (Ipc), anodik pik potansiyeli (Epa) ve katodik pik potansiyeli (Epc) değerleri ise Tablo 1'de verilmiştir. SPCE üzerine ERGO'nun modifikasyonu ile yalın SPCE elektrotuna göre elektronik iletkenliğin artışıyla birlikte Ipa ve Ipc değerlerinin arttığı da görülmektedir. ERGO, elektronik iletkenliği artırıcı yönde etki etmiş̧tir. SPCE/ERGO elektrotu yüzeyinde PTH filminin oluşturulmasıyla pik akımlarında gözlenen azalış, PTH'nin elektrot yüzeyine kaplandığını ve polimerin film kalınlığına bağlı olarak difüzyonu azaltıcı yönde etki ettiğini göstermektedir. PTH'nin elektrot formülasyonunda yer almasıyla pik potansiyelleri negatif yöne kaymış ve PTH elektrokatalitik etki göstermiştir. SPCE/ERGO/PTH elektrotu üzerinde AuNP'lerin elektrodepozisyonu ile hazırlanan SPCE/ERGO/PTH/AuNP elektrotunda anodik pik akımı artmış, pik potansiyeli ise negatif yöne kaymıştır. Pik potansiyelindeki bu kayma AuNP'nin elektrokatalitik etki gösterdiğini belirtmektedir. ERGO, PTH ve AuNP materyallerinin birlikte elektrot formülasyonunda yer alması sinerjik bir etki göstererek elektronik iletkenliği artırmış, aynı zamanda elektrokatalitik etki de göstermiştir $[15,35,44]$. Şekil 5B'de SPCE/ERGO/PTH/AuNP elektrotunun $5 \mathrm{mM}$ 


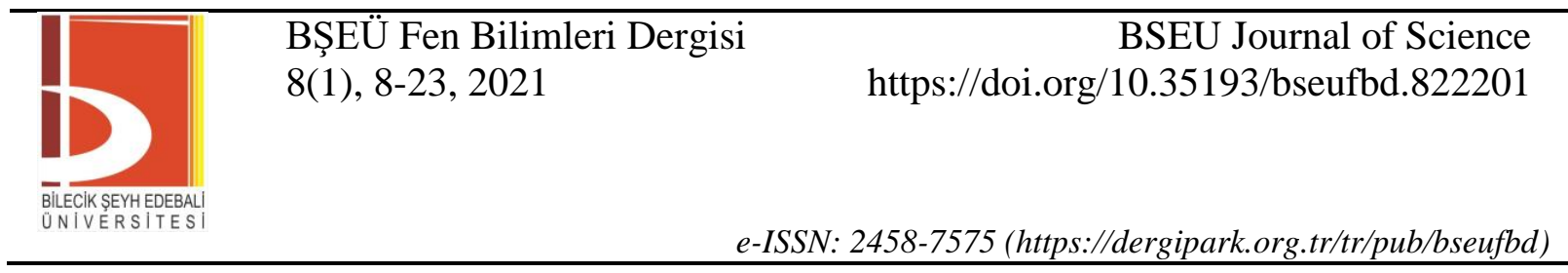

$\left[\mathrm{Fe}(\mathrm{CN})_{6}\right]^{-3 /-4}(1 \mathrm{M} \mathrm{KCl})$ çözeltisinde farklı tarama hızlarında $\left(10,25,50,75,100\right.$ ve $\left.125 \mathrm{mV} \mathrm{s}^{-1}\right)$ elde edilen dönüşümlü voltamogramları yer almaktadır. Tarama hızı arttıkça, Ipa ve Ipc değerleri de doğrusal olarak artmıştır (Şekil 5B, iç grafikler). Bu durum elektrokimyasal prosesin difüzyon kontrollü olduğunu göstermektedir.
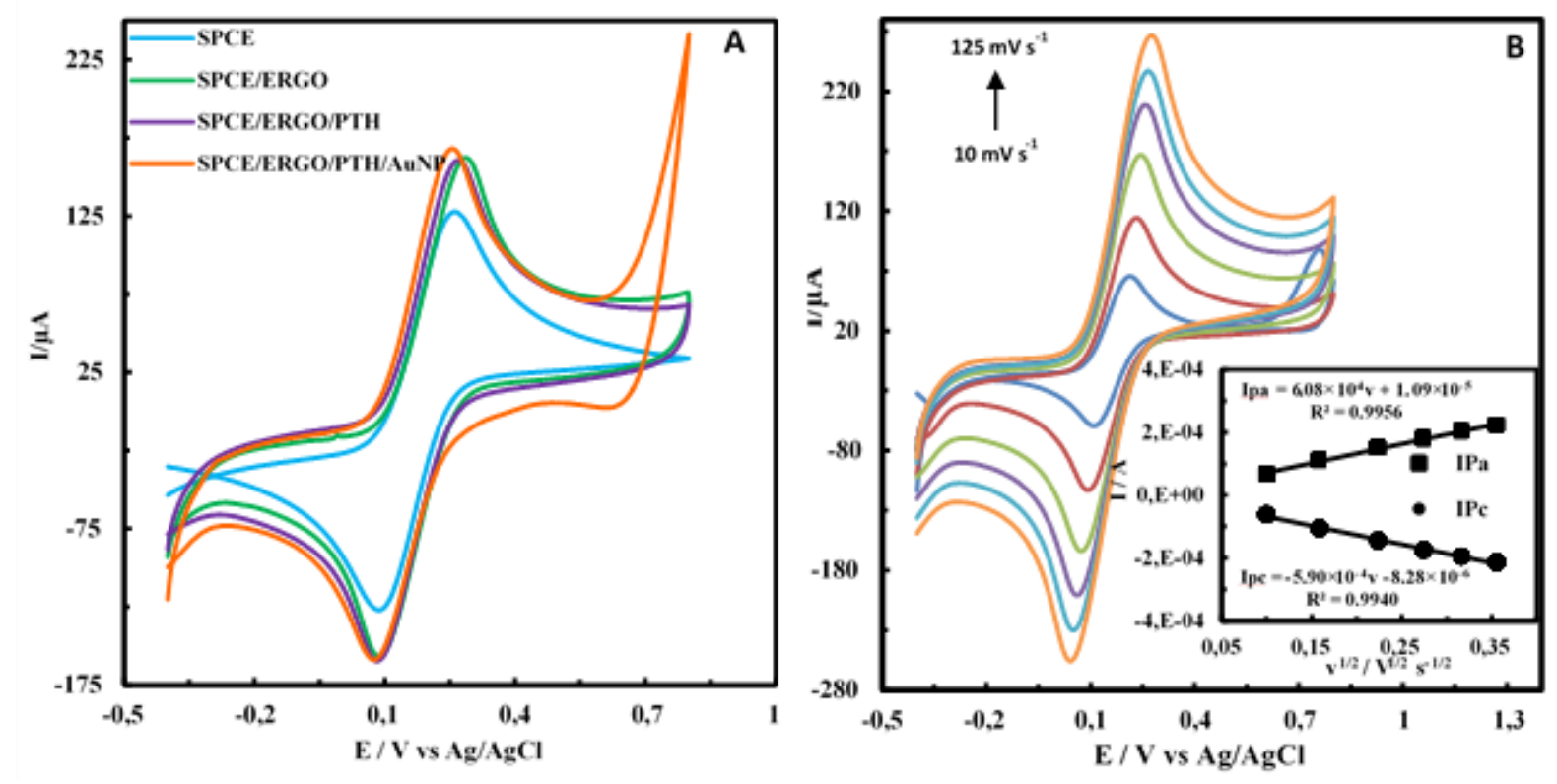

Sekil 5 (A) $5 \mathrm{mM}\left[\mathrm{Fe}(\mathrm{CN})_{6}\right]^{-3 / 4}(1 \mathrm{M} \mathrm{KCl})$ çözeltisinde SPCE, SPCE/ERGO, SPCE/ERGO/PTH ve SPCE/ERGO/PTH/AuNP elektrotlarının (B) SPCE/ERGO/PTH/AuNP elektrotunun farklı tarama hızlarında elde edilen dönüşümlü voltamogramları (tarama hızları: 10, 25, 50, 75, 100 ve $125 \mathrm{mV} \mathrm{s}^{-1}$ ), İç grafikler: dönüşümlü voltamogramlardan elde edilen pik akımları-tarama hızı grafikleri

Tablo 1. SPCE/ERGO/PTH/AuNP elektrotunun hazırlanma basamaklarında dönüşümlü voltamogramlardan elde edilen Ep ve Ip değerleri

\begin{tabular}{lcccc}
\hline & Epa $(\mathbf{V})$ & Ipa $(\boldsymbol{\mu A})$ & Epc $(\mathbf{V})$ & Ipc $(\boldsymbol{\mu A})$ \\
\hline SPCE & 0.262 & 133.3 & 0.086 & -127.9 \\
SPCE/ERGO & 0.284 & 144.7 & 0.084 & -142.9 \\
SPCE/ERGO/PTH & 0.266 & 142.5 & 0.082 & -140.1 \\
SPCE/ERGO/PTH/AuNP & 0.252 & 145.6 & 0.074 & -125.9 \\
\hline
\end{tabular}

\section{SPCE/ERGO/PTH/AuNP Elektrotlarinda DA, NADH ve AA'nin Elektroyükseltgenmesi}

Çalışmanın bu kısmında DA, NADH ve AA'nın SPCE, SPCE/ERGO, SPCE/ERGO/PTH ve SPCE/ERGO/PTH/AuNP elektrotları üzerindeki elektrokimyasal davranışları incelenmiştir. Bu amaçla $1 \mathrm{mM}$ DA, NADH ve AA çözeltilerine dönüşümlü voltametri uygulanmıştır. Elde edilen voltamogramlar Şekil 6'da, voltamogramlardan elde edilen Ip ve Ep değerleri ise Tablo 2'de verilmiştir. Yalın SPCE elektrotunda DA'nın Epa değeri $+0.158 \mathrm{~V}$ iken SPCE/ERGO elektrotunda bu değer artmıştır $(+0.180 \mathrm{~V})$. Ipa değeri ise ERGO'nun modifikasyonu ile azalmıştır. SPCE/ERGO/PTH elektrotunda Epa değeri $(+0.234 \mathrm{~V})$ artarken, Ipa değeri de SPCE/ERGO'da gözlenen Ipa değerine göre artmıştır. SPCE/ERGO/PTH/AuNP elektrotunda ise Epa (+0.144 V) azalmış, Ipa değeri $88.91 \mu \mathrm{A}$ 'e artmıştır (yaklaşık 2 kat). DA'nın redoks pikleri SPCE/ERGO/PTH/AuNP elektrotunda daha belirgindir. Bu sonuçlara göre SPCE/ERGO ve SPCE/ERGO/PTH elektrotları, DA'nın elektroyükseltgenmesinde fazla etki göstermezken, SPCE/ERGO/PTH/AuNP elektrotu DA'ya karş1 elektrokatalitik etki göstermiştir. GCE/AuNP/PTH elektrotunda DA'nın elektroyükseltgenmesinin incelendiği bir çalışmada PTH ve AuNP'nin sinerjik bir etki göstererek elektroaktif yüzey alanını ve elektron transferini artırdığı bildirilmiştir [47]. Yalın SPCE'ye göre SPCE/ERGO/PTH/AuNP elektrotunda Epa değeri daha düşüktür. Bu etki, elektrot formülasyonunda yer alan SPCE, ERGO ve AuNP'nin sinerjik etkisi ve PTH'nin medyatör olarak görev yapması nedeniyledir. Manyetik kitosan mikroküreler (MCMS) ve PTH ile modifiye edilmiş camsı karbon elektrotlarda (GCE) DA'nın elektroyükseltgenmesinin incelendiği bir çalışmada PTH'nin DA'nın elektroyükseltgenmesinde medyatör olarak rol oynadığı rapor edilmiştir [48]. Tabaka tabaka birleştirilmiş çok 


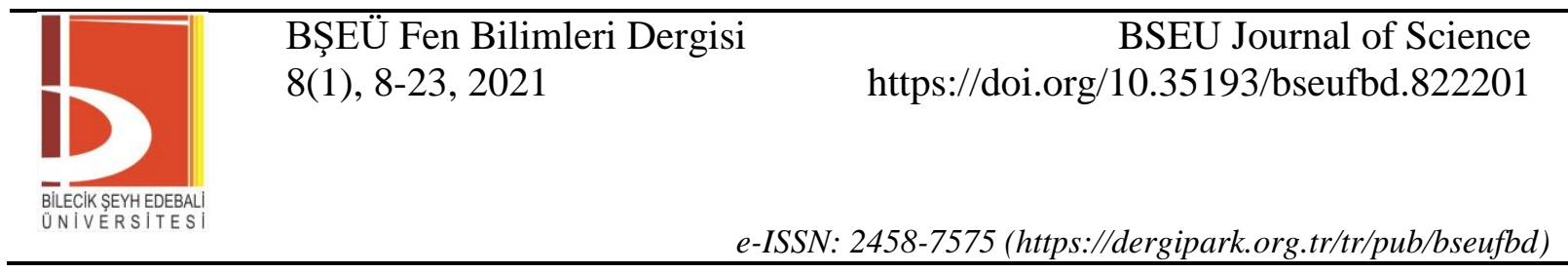

katmanlı RGO ve AuNP ile modifiye edilen GCE'lerde DA'nın elektroyükseltgenmesinin incelendiği başka bir çalışmada ise AuNP ve ERGO'nun birlikte sinerjik etki yaptığı bildirilmiştir [3].
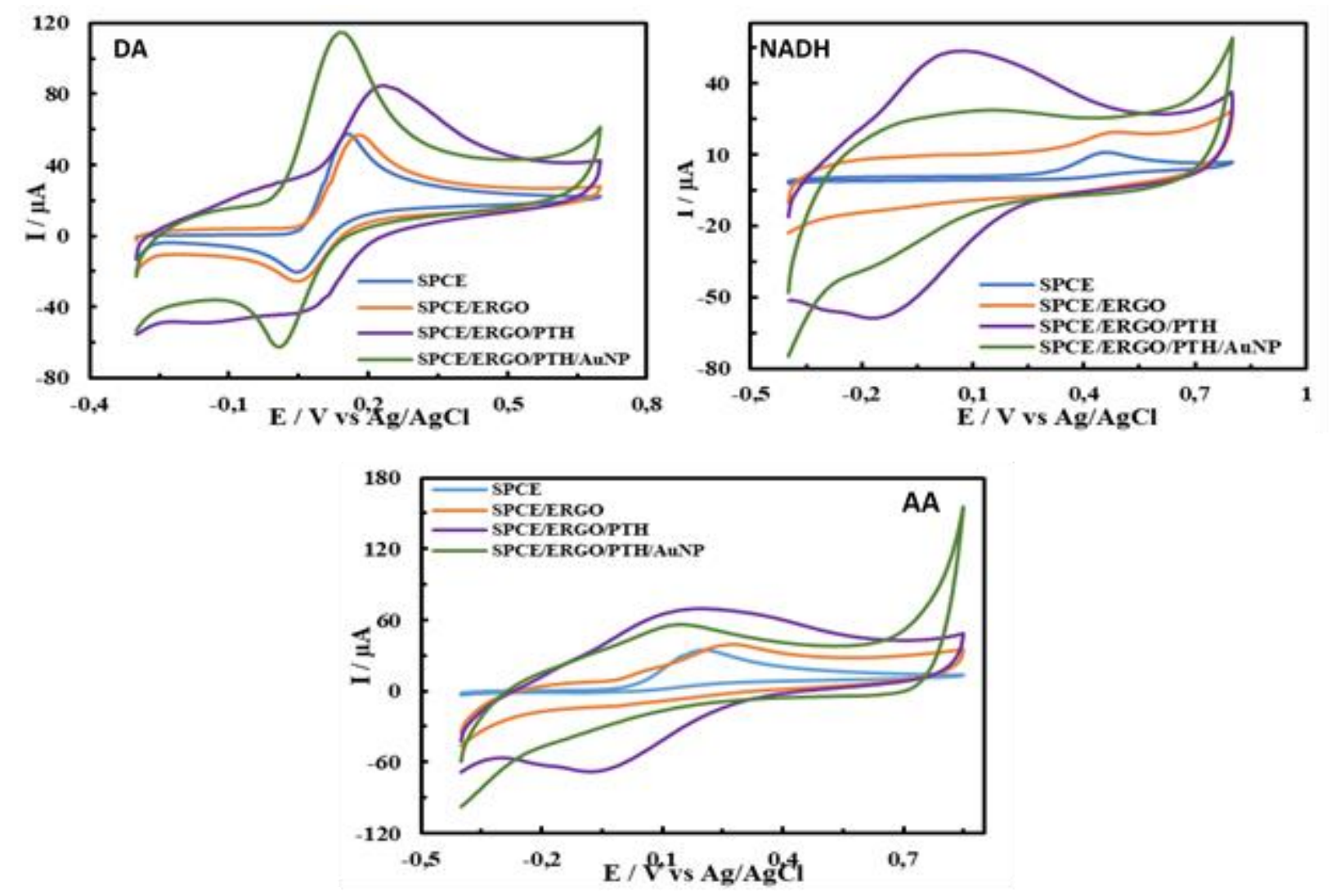

Şekil 6. SPCE, SPCE/ERGO, SPCE/ERGO/PTH ve SPCE/ERGO/PTH/AuNP elektrotlarının 1 mM DA, NADH ve AA çözeltilerinde elde edilen dönüşümlü voltamogramları (50 mM pH 7.0 PBS, $0.1 \mathrm{M} \mathrm{KCl}$; tarama hızı: $100 \mathrm{mV} \mathrm{s}^{-1}$ )

NADH'nın elektroyükseltgenmesi incelendiğinde, yalın SPCE elektrotunda NADH'nin Epa değeri $+0.460 \mathrm{~V}$ iken, SPCE/ERGO elektrotunda bu değer $+0.466 \mathrm{~V}$ 'dur. Ipa değeri ise SPCE/ERGO elektrotunda azalmıştır. PTH'nin ERGO ile birlikte elektrot formülasyonunda yer almasıyla NADH'nin anodik pik potansiyeli +0.058 V'a azalırken, anodik pik akımı $31.02 \mu \mathrm{A}^{\prime}$ e artmıştır. Epa değerindeki 0.408 V'luk azalış ve Ipa değerindeki yaklaşık 10 katlık artış, PTH'nin NADH'nin elektroyükseltgenmesinde elektrokatalitik etki gösterdiğini belirtmektedir. NADH'nin elektroyükseltgenmesinde PTH medyatör olarak davranmıştır [49]. ERGO ve PTH ile modifiye edilen GCE'lerde NADH'nin elektroyükseltgenmesinin incelendiği bir çalışmada, PTH ve ERGO'nun NADH'nin elektroyükseltgenmesine sinerjik katalitik bir etki gösterdiği bildirilmiştir [50]. SPCE/ERGO/PTH/AuNP elektrotunda NADH'nin Epa değeri +0.122 V'a artmış, Ipa değeri de azalmıştır. AuNP, PTH'nin NADH'ye karşı olan medyatör etkisini azaltıcı yönde etki göstermiş olmasına karşın, yalın SPCE'ye göre SPCE/ERGO/PTH/AuNP elektrotunda Epa değeri +0.338 V azalmıştır. SPCE/ERGO, NADH'nin elektroyükseltgenmesinde elektrokatalitik etki göstermezken, SPCE/ERGO/PTH ve SPCE/ERGO/PTH/AuNP elektrotları NADH'ye karşı elektrokatalitik etki göstermiştir. Yalın SPCE'lerde AA'nın anodik pik potansiyeli +0.268 V'da gözlenirken, SPCE/ERGO'da Epa +0.278 V'da gözlenmiştir ve Ipa değeri de azalmıştır. SPCE/ERGO/PTH elektrotunda AA'nın anodik pik potansiyeli +0.188 V'a azalırken, Ipa $35.18 \mu \mathrm{A}^{\prime}$ e artmıştır (yaklaşık 1.5 kat). Epa'daki azalış ve Ipa'daki artış, PTH'nin AA'nın elektroyükseltgenmesinde elektrokatalitik etki yaptığının ve medyatör olarak davrandığının bir göstergesidir. AA'nın SPCE/ERGO/PTH/AuNP elektrotundaki Epa değeri +0.122 V'a artarken, Ipa değeri biraz azalmıştır. Yalın SPCE'ye göre SPCE/ERGO/PTH/AuNP elektrotunda Epa değeri $+0.146 \mathrm{~V}$ azalmıştır. 
Tablo 2. 1 mM DA, NADH ve AA'nın çeşitli elektrot formülasyonlarında dönüşümlü voltamogramlarından elde edilen Ep ve Ip değerleri

\begin{tabular}{|c|c|c|c|c|c|}
\hline Analit & Elektrot formülasyonu & Epa $(V)$ & Iра $(\mu \mathbf{A})$ & $\overline{E p c}(V)$ & Ipc $(\mu \mathrm{A})$ \\
\hline \multirow{4}{*}{ DA } & SPCE & 0.158 & 51.27 & 0.046 & -27.15 \\
\hline & SPCE/ERGO & 0.180 & 46.7 & 0.046 & -27.25 \\
\hline & SPCE/ERGO/PTH & 0.234 & 50.53 & 0.068 & -25.13 \\
\hline & SPCE/ERGO/PTH/AuNP & 0.144 & 88.91 & 0.008 & -47.77 \\
\hline \multirow[t]{4}{*}{ NADH } & SPCE & 0.460 & 7.17 & - & - \\
\hline & SPCE/ERGO & 0.466 & 3.46 & - & - \\
\hline & SPCE/ERGO/PTH & 0.058 & 31.02 & - & - \\
\hline & SPCE/ERGO/PTH/AuNP & 0.122 & 6.68 & - & - \\
\hline \multirow[t]{4}{*}{$\mathbf{A A}$} & SPCE & 0.268 & 29.05 & - & - \\
\hline & SPCE/ERGO & 0.278 & 21.77 & - & - \\
\hline & SPCE/ERGO/PTH & 0.188 & 35.18 & - & - \\
\hline & SPCE/ERGO/PTH/AuNP & 0.122 & 32.14 & - & - \\
\hline
\end{tabular}

DA, NADH ve AA'nın elektroyükseltgenmesine ERGO, PTH ve AuNP'nin etkilerini şu şekilde özetleyebiliriz: ERGO, her üç analit için de elektrokatalitik etki göstermemiştir. PTH'nin ERGO ile birlikte elektrot formülasyonunda yer almasıyla DA, NADH ve AA'nın elektroyükseltgenmesinde elektrokatalitik etki göstermiş ve PTH medyatör olarak davranmıştır. AuNP'nin elektrot formülasyonundaki varlığı NADH'nin elektroyükseltgenmesinde medyatör olarak davranan PTH'nin etkisini azaltırken, DA ve AA'da elektrokatalitik etki göstermiştir. DA, NADH ve AA varlığında anodik pik akımlarının artması, DA, NADH ve AA'nın çözeltiden SPCE/ERGO/PTH/AuNP elektrotlarının yüzeyine doğru difüzlenerek yükseltgendiğini ve buna karşın yüzeydeki PTH'nin indirgendiğini gösterir. Bu elektrokimyasal işlem zinciri şöyle formüle edilebilir:

$$
\begin{aligned}
& \mathrm{PTH}_{\text {(ind) }} \longrightarrow \mathrm{PTH}_{(\text {yük })}+2 \mathrm{H}^{+}+2 \mathrm{e}^{-} \\
& \mathrm{DA}_{(\text {ind })}+\mathrm{PTH}_{(\text {yük })} \longrightarrow \mathrm{DA}_{(\text {yük })}+\mathrm{PTH}_{(\text {ind) }} \\
& \mathrm{NADH}_{(\text {ind) }}+\mathrm{PTH}_{(\text {yük })} \longrightarrow \mathrm{NAD}_{(\text {yük })}+\mathrm{PTH}_{(\text {ind })} \\
& \mathrm{AA}_{(\text {(ind) }}+\mathrm{PTH}_{(\text {yük })} \longrightarrow \mathrm{AA}_{(\text {yük })}+\mathrm{PTH}_{(\text {ind })}
\end{aligned}
$$
gösterilmiştir.

SPCE/ERGO/PTH/AuNP elektrotlarında DA, NADH ve AA’nın tüm yükseltgenme reaksiyonları aşağıda

$$
\begin{aligned}
& \mathrm{DA}_{(\text {ind })} \longrightarrow \mathrm{DA}_{(\text {yük })}+2 \mathrm{H}^{+}+2 \mathrm{e}^{-} \\
& \mathrm{NADH}_{\text {(ind) }} \longrightarrow \mathrm{NAD}_{\text {(yük) }}^{+}+\mathrm{H}^{+}+2 \mathrm{e}^{-} \\
& \mathrm{AA}_{(\text {ind })} \longrightarrow \mathrm{AA}_{(\text {yük })}+2 \mathrm{H}^{+}+2 \mathrm{e}^{-}
\end{aligned}
$$

Tablo 3'de son yıllarda ERGO, PTH ve/veya AuNP ile modifiye edilen elektrotlarda elde edilen DA, NADH ve AA'nın Epa değerleri verilmiştir. Çalışmamızda elde edilen Epa değerlerinin literatürde elde edilen Epa değerlerinden daha düşük potansiyelde olduğu görülmektedir. Bu sonuçlar ERGO, PTH ve AuNP'nin sinerjik bir etki göstererek DA, NADH ve AA’nın elektroyükseltgenmesinde elektrokatalitik bir etki yaptığını göstermektedir. 
Tablo 3. Son yıllarda ERGO, PTH ve/veya AuNP ile modifiye edilen elektrotlarda elde edilen DA, NADH ve AA'nın Epa değerleri

\begin{tabular}{llll}
\hline Analit & Elektrot formülasyonu & Epa (V) & Kaynak \\
\hline DA & GCE/FA/ERGO & 0.312 & {$[1]$} \\
& GCE/\{AuNPs/RGO $\}_{20}$ & 0.171 & {$[3]$} \\
& GCE/PTH/AuNP & 0.450 & {$[47]$} \\
& Au/GR-AuAg & 0.200 & {$[51]$} \\
SPCE/ERGO/PTH/AuNP & 0.144 & Bu çalışma \\
& GCE/ERGO/PTH & 0.37 & {$[50]$} \\
& GCE/Chitosan/RGO/AuNP & 0.36 & {$[52]$} \\
& GCE/RGO/AuNP & 0.52 & {$[53]$} \\
SPE/PAH/ERGO/AuNP & 0.51 & {$[54]$} \\
GCE/CRGO & 0.40 & {$[55]$} \\
& SPCE/ERGO/PTH/AuNP & 0.122 & Bu çalışma \\
& GCE/RGO & 0.20 & {$[16]$} \\
& PIGE/Fc-TH & 0.325 & {$[56]$} \\
GCE/AuNP/ERGO/Chitosan & 0.27 & {$[57]$} \\
& SPCE/ERGO/PTH/AunP & 0.122 & Bu çalışma
\end{tabular}

GCE: camsı karbon elektrot, AuNP: altın nanopartikül, RGO: indirgenmiş grafen oksit, Au: altın elektrot, GR: grafen, AuAg: altın-gümüş kompozit, PTH: politiyonin, SPCE: yüzey baskılı karbon elektrot, ERGO: elektrokimyasal olarak indirgenmiş grafen oksit, PAH: poliallilaminhidroklorür, CRGO: kimyasal olarak indirgenmiş grafen oksit, PIGE: parafin mumu emdirilmiş grafit elektrot, Fc-TH: ferrosen-tiyonin, FA: ferulik asit

Şekil 7'de $1 \mathrm{mM}$ DA, NADH ve AA çözeltilerinin (50 mM pH 7.0 fosfat tamponu, $0.1 \mathrm{M} \mathrm{KCl})$ SPCE/ERGO/PTH/AuNP elektrotları üzerinde farklı tarama hızlarında (10, 20, 40, 50, 60, 80 ve $\left.100 \mathrm{mV} \mathrm{s}^{-1}\right)$ elde edilen dönüşümlü voltamogramları verilmiştir. Tarama hızı arttıkça DA'nın yükseltgenme ve indirgenme pik akımları, NADH ve AA'nın ise yükseltgenme pik akımları artmıştır. Voltamogramlardan elde edilen pik akımlarına karşı çizilen tarama hızının karekökü grafikleri (Şekil 7, iç grafikler) doğrusaldır. Bu sonuçlara göre DA, NADH ve AA'nın SPCE/ERGO/PTH/AuNP elektrotları üzerindeki elektroyükseltgenmeleri difüzyon kontrollü prosestir [1, 3, 14-15, 49, 53, 57-58]. Difüzyon kontrollü elektrokimyasal prosesler için RandlesSevcik eşitliği [59] kullanılarak analitlerin difüzyon katsayısı hesaplanabilir. Randles-Sevcik eşitliği kullanılarak $1 \mathrm{mM}$ DA, $1 \mathrm{mM}$ NADH ve $1 \mathrm{mM}$ AA'nın difüzyon katsayıları sırasıyla $3.37 \times 10^{-8}, 7.79 \times 10^{-9}$ ve $1.51 \times 10^{-8}$ olarak hesaplanmıştır. SPCE/ERGO/PTH/AuNP'lerin yüzeyi ve çözelti arasında meydana gelen DA, NADH ve AA'nın elektroyükseltgenmesi için elektron-transfer katsayısı $(\alpha)$ aşağıdaki eşitlikten bulunabilir [60]:

$$
\mathrm{Ep}=(\mathrm{RT} / 2 \alpha \mathrm{F}) \ln v+\text { sabit }
$$

Burada $\mathrm{E}_{\mathrm{p}}$ pik potansiyelini, $v$ potansiyel tarama hızını ifade eder. DA, NADH ve AA için anodik pik potansiyelleri tüm tarama hızı aralığında lnv’ye karşı doğrusal olarak değişmektedir. Bu değişim için doğrusal regresyon denklemleri DA, NADH ve AA için sirasılla $\mathrm{E}_{\mathrm{pa}}=0.0386 \ln v+0.3035, \mathrm{r}=0.9991 ; \mathrm{E}_{\mathrm{pa}}=0.018 \ln v+$ $0.104, \mathrm{r}=0.9884 ; \mathrm{E}_{\mathrm{pa}}=0.0338 \ln v+0.2207, \mathrm{r}=0.9954$ şeklindedir. Eşitlik 9 kullanılarak $1 \mathrm{mM} \mathrm{DA}, 1 \mathrm{mM}$ NADH ve $1 \mathrm{mM}$ AA için $\alpha$ değerleri hesaplanmış ve bu değerler sirasıyla $0.327,0.701,0.373$ olarak bulunmuştur. 


\begin{tabular}{|c|c|c|}
\hline & $\begin{array}{l}\text { BŞEÜ Fen Bilimleri Dergisi } \\
8(1), 8-23,2021\end{array}$ & $\begin{array}{r}\text { BSEU Journal of Science } \\
\text { https://doi.org/10.35193/bseufbd.822201 }\end{array}$ \\
\hline ERSI & & 2458-7575 (https://dergipark.org.tr/tr/pub/bseufbd) \\
\hline
\end{tabular}
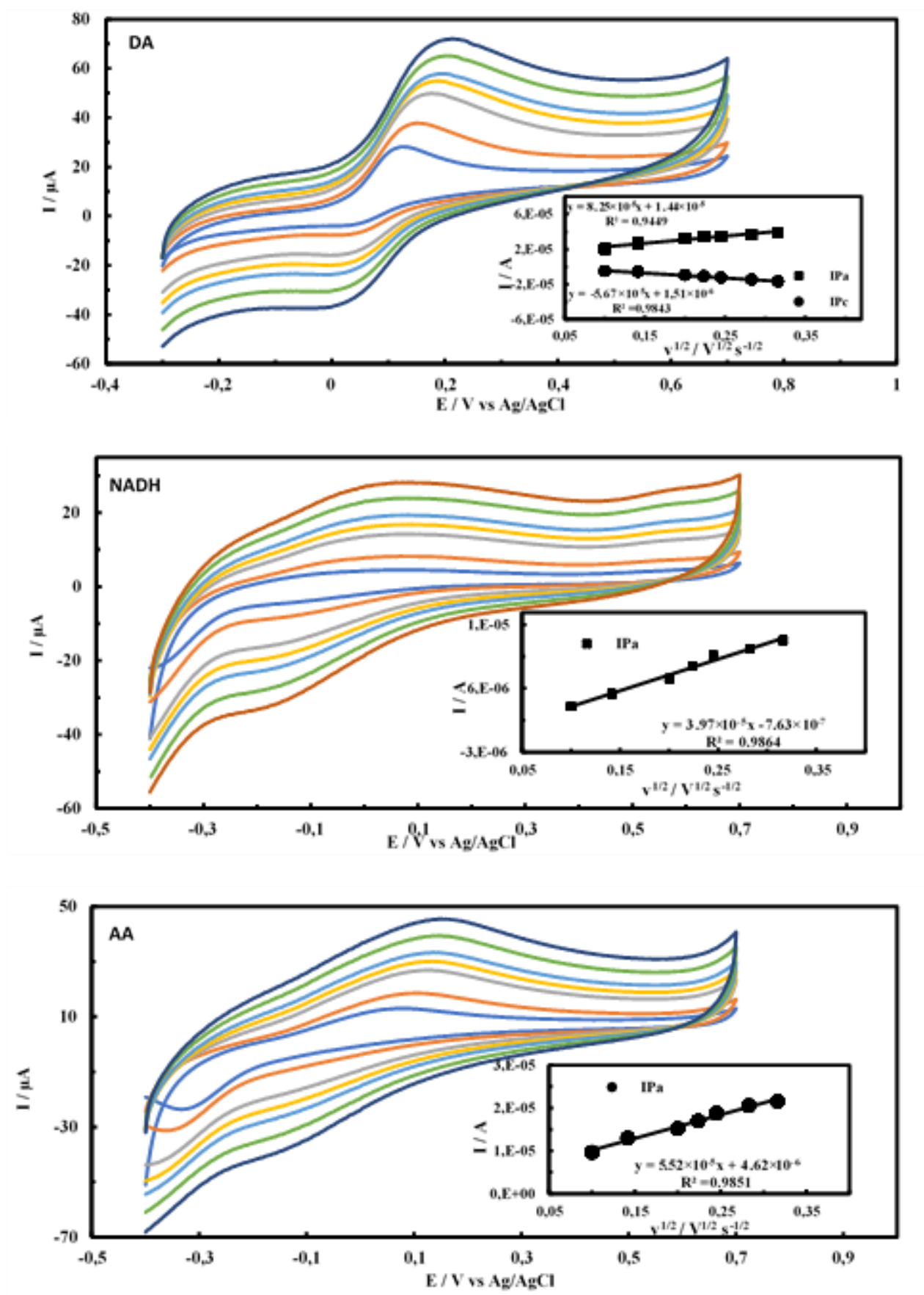

Şekil 7. SPCE/ERGO/PTH/AuNP elektrotlarının $1 \mathrm{mM}$ DA, NADH ve AA çözeltilerinde farklı tarama hızlarında elde edilen dönüşümlü voltamogramları (50 mM pH 7.0 PBS, $0.1 \mathrm{M} \mathrm{KCl}$; tarama hizları: $10,20,40,50,60,80$ ve $100 \mathrm{mV} \mathrm{s}^{-1}$ )

DA, NADH ve AA'nın elektroyükseltgenmelerine pH'nın etkisini incelemek için $50 \mathrm{mM}$ derişimde farklı pH'larda (4-8 aralığında) asetat ve fosfat tampon çözeltileri hazırlanmıştır. Her bir farklı pH'ya sahip tampon çözeltiler kullanılarak $1 \mathrm{mM}$ sabit derişimde DA, NADH ve AA çözeltileri hazırlanmış ve bu çözeltilere SPCE/ERGO/PTH/AuNP elektrotları kullanılarak $100 \mathrm{mVs}^{-1}$ tarama hızında dönüşümlü voltametri uygulanmıştır. DA, NADH ve AA için farklı pH'larda elde edilen dönüşümlü voltamogramlar ve anodik pik potansiyellerine karşı $\mathrm{pH}$ grafikleri Şekil 8'de verilmiştir. Her üç analit için de Epa değerlerinin pH artışı ile azaldığı hem voltamogramlardan hem de grafiklerden anlaşılmaktadır. Epa değerlerinin kayması, elektroyükseltgenmenin pH'ya bağlı olması nedeniyledir $[1,16,61]$. Şekil 8'de verilen Epa-pH grafiklerinden elde edilen doğruların eğimi DA, NADH ve AA için sırasıyla $-52.2 \mathrm{mV} / \mathrm{pH},-22.7 \mathrm{mV} / \mathrm{pH}$ ve $-21.1 \mathrm{mV} / \mathrm{pH}$ 'dır. 


\begin{tabular}{|c|c|c|}
\hline & $\begin{array}{l}\text { BŞEÜ Fen Bilimleri Dergisi } \\
8(1), 8-23,2021\end{array}$ & $\begin{array}{r}\text { BSEU Journal of Science } \\
\text { https://doi.org/10.35193/bseufbd.822201 }\end{array}$ \\
\hline & & 2458-7575 (https://dergipark.org.tr/tr/pub/bseufbd) \\
\hline
\end{tabular}

DA için elde edilen $-52.2 \mathrm{mV} / \mathrm{pH}$ değeri Nerst eşitliği için verilen teorik değere yakındır $(-59.2 \mathrm{mV} / \mathrm{pH}, 25$ ${ }^{\circ} C^{\prime}$ de). Buna göre, SPCE/ERGO/PTH/AuNP elektrotunda DA'nın elektroyükseltgenme reaksiyonu protona bağımlıdır ve transfer edilen elektron sayısı proton sayısına eşittir [1]. DA'nın elektroyükseltgenmesi 2 elektronlu-2 protonlu prosesi içerir [3]. NADH için elde edilen $-22.7 \mathrm{mV} / \mathrm{pH}$ değeri ise $-59.2 \mathrm{mV} / \mathrm{pH}$ teorik değerin yaklaşık yarısına eşittir. NADH'nin SPCE/ERGO/PTH/AuNP elektrotunda elektroyükseltgenmesi 2 elektronlu-1 protonlu prosesi içerir [62]. AA bir diasit $\left(\mathrm{H}_{2} \mathrm{~A}\right)$ olduğu ve 2 basamakta ayrıştı̆̆ için $\left(\mathrm{pKa}_{1}=4.1\right.$, $\mathrm{pKa}_{2}=11.8$ ), elektroyükseltgenmesi $\mathrm{pH}$ 'ya bağımlıdır $[16,61]$. AA'nın elektrooksidasyonunun 2 elektronlu-2 protonlu proses olduğu bilinmektedir [63, 64].
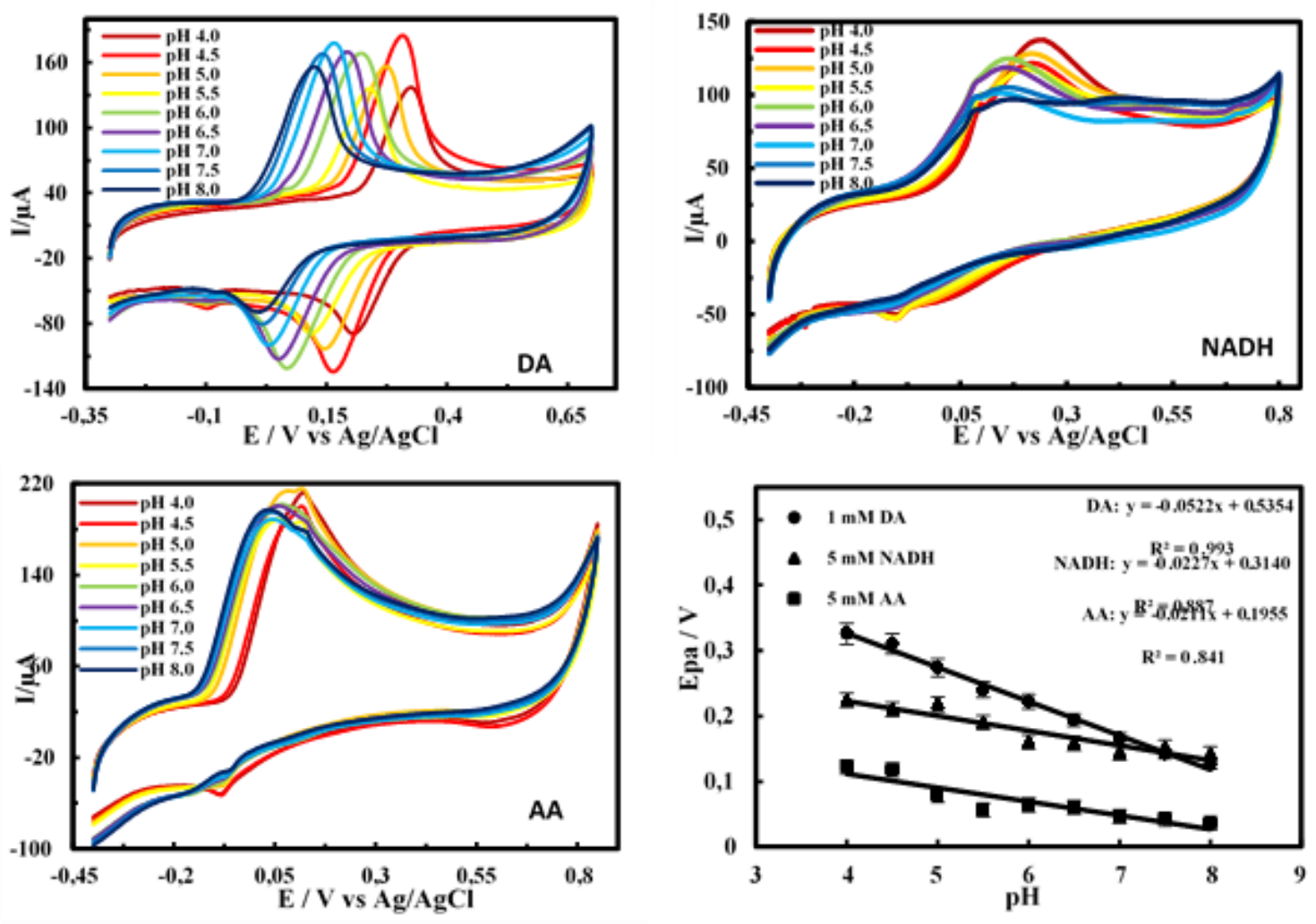

Şekil 8. SPCE/ERGO/PTH/AuNP elektrotunun $1 \mathrm{mM}$ DA, $5 \mathrm{mM}$ NADH ve $5 \mathrm{mM}$ AA içeren farklı pH'lardaki tampon çc̈zeltilerinde $(0.1$ $\mathrm{M} \mathrm{KCl}$ ) elde edilen dönüşümlü voltamogramları (tarama hızı: $100 \mathrm{mV} \mathrm{s}^{-1}$ ) ve dönüşümlü voltamogramlardan elde edilen anodik pik potansiyeli-pH grafikleri

\section{SONUÇLAR}

Bu çalışmada tek kullanımlık yüzey baskılı karbon elektrotlar; ERGO, PTH ve AuNP ile başarılı bir şekilde modifiye edilmiş ve elektrokimyasal karakterizasyonları yapılmıştır. SPCE/ERGO/PTH/AuNP elektrotları üzerinde DA, NADH ve AA'nın elektroyükseltgenmelerinde PTH'nin üç analit için de medyatör olarak görev yaptığı belirlenmiştir. DA, NADH ve AA'nın elektroyükseltgenmelerinde ERGO, PTH ve AuNP'nin birlikte sinerjik elektrokatalitik etki gösterdiği sonucuna varılmıştır. DA, NADH ve AA'nın difüzyon katsayıları (D) sirasıly $3.37 \times 10^{-8}, 7.79 \times 10^{-9}$ ve $1.51 \times 10^{-8}$ olarak, elektron transfer katsayıları $(\alpha)$ ise sırasıyla $0.327,0.701$ ve 0.373 olarak hesaplanmıştır. DA ve AA'nın elektroyükseltgenmesinde gerçekleşen elektrokimyasal prosesin 2 elektronlu-2 protonlu, NADH'nin ise 2 elektronlu-1 protonlu olduğu gözlenmiştir. DA, NADH ve AA'nın elektroyükseltgenmesinin pH'ya bağımlı olduğu bildirilmiştir. Bu çalışmada hazırlanan SPCE/ERGO/PTH/AuNP elektrotları ile DA, NADH ve AA'nın elektrokimyasal tayini için tek kullanımlık, düşük maliyetli ve pratik sensör geliştirilebilir. 


\begin{tabular}{|c|c|c|}
\hline & $\begin{array}{l}\text { BŞEÜ Fen Bilimleri Dergisi } \\
8(1), 8-23,2021\end{array}$ & $\begin{array}{r}\text { BSEU Journal of Science } \\
\text { DOI: } 10.35193 / \text { bseufbd. } 822201\end{array}$ \\
\hline $\begin{array}{l}\text { BILECIK SEYH EDEBALI } \\
\text { UNIVERSITESI }\end{array}$ & & 8-7575 (http://dergipark.gov.tr/bseufbd) \\
\hline
\end{tabular}

\section{KAYNAKLAR}

[1] Han, H. S., Seol, H., Kang, D. H., Ahmed, M. S., You, J. M. \& Jeon, S. (2014). Electrochemical oxidation and determination of dopamine in the presence of AA using ferulic acid functionalized electrochemically reduced graphene. Sensors and Actuators B: Chemical, 204, 289-296.

[2] Liu, A., Honma, I. \& Zhou, H. (2007). Simultaneous voltammetric detection of dopamine and uric acid at their physiological level in the presence of ascorbic acid using poly (acrylic acid)-multiwalled carbonnanotube composite-covered glassy-carbon electrode. Biosensors and Bioelectronics, 23(1), 74-80.

[3] Liu, S., Yan, J., He, G., Zhong, D., Chen, J., Shi, L., Zhou, X. \& Jiang, H. (2012). Layer-by-layer assembled multilayer films of reduced graphene oxide/gold nanoparticles for the electrochemical detection of dopamine. Journal of Electroanalytical Chemistry, 672, 40-44.

[4] Liu, A., Honma, I. \& Zhou, H. (2005). Amperometric biosensor based on tyrosinase-conjugated polysacchride hybrid film: Selective determination of nanomolar neurotransmitters metabolite of 3, 4dihydroxyphenylacetic acid (DOPAC) in biological fluid. Biosensors and Bioelectronics, 21(5), 809816.

[5] Wightman, R. M., May, L. J. \& Michael, A. C. (1988). Detection of dopamine dynamics in the brain. Analytical Chemistry, 60(13), 769A-793A.

[6] Bergel, A., Souppe, J. \& Comtat, M. (1989). Enzymatic amplification for spectrophotometric and electrochemical assays of NAD+ and NADH. Analytical Biochemistry, 179(2), 382-388.

[7] Rusling, J. F. (Ed.). (2003). Biomolecular films: design, function, and applications. CRC Press, New York, 499.

[8] Omar, F. S., Duraisamy, N., Ramesh, K. \& Ramesh, S. (2016). Conducting polymer and its composite materials based electrochemical sensor for Nicotinamide Adenine Dinucleotide (NADH). Biosensors and Bioelectronics, 79, 763-775.

[9] Gunes, M. \& Dilgin, Y. (2019). Flow injection amperometric determination of NADH at a calmagitemodified pencil graphite electrode. Monatshefte Fur Chemie, 150(8), 1425-1432.

[10] Romay, C. H., Armesto, J., Remirez, D., Gonzalez, R., Ledon, N. \& Garcia, I. (1998). Antioxidant and anti-inflammatory properties of C-phycocyanin from blue-green algae. Inflammation Research, 47(1), 36-41.

[11] Bhagavan, N. V. (2001). Medical Biochemistry. $4^{\text {th }}$ ed. Elsevier, Netherlands, 331-363.

[12] Eitenmiller, R. R., Landen Jr, W. O. \& Ye, L. (2016). Vitamin analysis for the health and food sciences. CRC press, New York.

[13] Basu, T. K. \& Dickerson, J. W. T. (1996). Vitamin A. Vitamin A in human health and disease. Oxon: CAB International, 148-77.

[14] Altun, M., Bilgi Kamaç, M., Bilgi, A. \& Yılmaz, M. (2020). Dopamine biosensor based on screenprinted electrode modified with reduced graphene oxide, polyneutral red and gold nanoparticle. International Journal of Environmental Analytical Chemistry, 100(4), 451-467.

[15] Bilgi Kamaç, M., Kıymaz Onat, E. \& Yılmaz, M. (2020). A new disposable amperometric NADH sensor based on screen-printed electrode modified with reduced graphene oxide/polyneutral red/gold nanoparticle. International Journal of Environmental Analytical Chemistry, 100(4), 419-431.

[16] de Faria, L. V., Lisboa, T. P., de Farias, D. M., Araujo, F. M., Machado, M. M., de Sousa, R. A., Matos, M. A. C., Munoz, R. A. A. \& Matos, R. C. (2020). Direct analysis of ascorbic acid in food beverage samples by flow injection analysis using reduced graphene oxide sensor. Food Chemistry, 126509.

[17] Ghica, M. E. \& Brett, C. M. (2010). The influence of carbon nanotubes and polyazine redox mediators on the performance of amperometric enzyme biosensors. Microchimica Acta, 170(3-4), 257-265.

[18] Barsan, M. M., Ghica, M. E. \& Brett, C. M. (2015). Electrochemical sensors and biosensors based on redox polymer/carbon nanotube modified electrodes: a review. Analytica Chimica acta, 881, 1-23.

[19] Pauliukaite, R., Ghica, M. E., Barsan, M. M. \& Brett, C. M. (2010). Phenazines and polyphenazines in electrochemical sensors and biosensors. Analytical Letters, 43(10-11), 1588-1608.

[20] Tanaka, K., Ikeda, S., Oyama, N., Tokuda, K. \& Ohsaka, T. (1993). Preparation of poly (thionine)modified electrode and its application to an electrochemical detector for the flow-injection analysis of NADH. Analytical Sciences, 9(6), 783-789.

[21] Mi, Q., Wang, Z. W., Chai, C. Y., Zhang, J., Zhao, B. \& Chen, C. Y. (2011). Multilayer structured immunosensor based on a glassy carbon electrode modified with multi-wall carbon nanotubes, polythionine, and gold nanoparticles. Microchimica Acta, 173(3-4), 459-467. 


\begin{tabular}{|c|c|c|}
\hline & $\begin{array}{l}\text { BŞEÜ Fen Bilimleri Dergisi } \\
\text { 8(1), 8-23, } 2021\end{array}$ & $\begin{array}{r}\text { BSEU Journal of Science } \\
\text { https://doi.org/10.35193/bseufbd.822201 }\end{array}$ \\
\hline & & 2458-7575 (https://dergipark.org.tr/tr/pub/bseufbd) \\
\hline
\end{tabular}

[22] Ghica, M. E. \& Brett, C. M. (2014). Poly (brilliant green) and poly (thionine) modified carbon nanotube coated carbon film electrodes for glucose and uric acid biosensors. Talanta, 130, 198-206.

[23] Martínez-García, G., Pérez-Julián, E., Agüí, L., Cabré, N., Joven, J., Yáñez-Sedeño, P. \& Pingarrón, J. M. (2017). An electrochemical enzyme biosensor for 3-hydroxybutyrate detection using screen-printed electrodes modified by reduced graphene oxide and thionine. Biosensors, 7(4), 50.

[24] Ye, Y., Xie, J., Ye, Y., Cao, X., Zheng, H., Xu, X. \& Zhang, Q. (2018). A label-free electrochemical DNA biosensor based on thionine functionalized reduced graphene oxide. Carbon, 129, 730-737.

[25] Stankovich, S., Dikin, D. A., Dommett, G. H., Kohlhaas, K. M., Zimney, E. J., Stach, E. A., Piner, R. D., Nguyen, S. T. \& Ruoff, R. S. (2006). Graphene-based composite materials. Nature, 442(7100), 282286.

[26] Patil, A. J., Vickery, J. L., Scott, T. B. \& Mann, S. (2009). Aqueous stabilization and self-assembly of graphene sheets into layered bio-nanocomposites using DNA. Advanced Materials, 21(31), 3159-3164.

[27] Wang, Y., Lu, J., Tang, L., Chang, H. \& Li, J. (2009). Graphene oxide amplified electrogenerated chemiluminescence of quantum dots and its selective sensing for glutathione from thiol-containing compounds. Analytical Chemistry, 81(23), 9710-9715.

[28] Liu, C., Alwarappan, S., Chen, Z., Kong, X. \& Li, C. Z. (2010). Membraneless enzymatic biofuel cells based on graphene nanosheets. Biosensors and Bioelectronics, 25(7), 1829-1833.

[29] Putzbach, W. \& Ronkainen, N. J. (2013). Immobilization techniques in the fabrication of nanomaterialbased electrochemical biosensors: A review. Sensors, 13(4), 4811-4840.

[30] Bilgi, M. \& Ayranci, E. (2018). Development of amperometric biosensors using screen-printed carbon electrodes modified with conducting polymer and nanomaterials for the analysis of ethanol, methanol and their mixtures. Journal of Electroanalytical Chemistry, 823, 588-592.

[31] Fanjul-Bolado, P., Hernández-Santos, D., Lamas-Ardisana, P. J., Martín-Pernía, A. \& Costa-García, A. (2008). Electrochemical characterization of screen-printed and conventional carbon paste electrodes. Electrochimica Acta, 53(10), 3635-3642.

[32] Wang, J., Tian, B., Nascimento, V. B. \& Angnes, L. (1998). Performance of screen-printed carbon electrodes fabricated from different carbon inks. Electrochimica Acta, 43(23), 3459-3465.

[33] Lee, S. X., Lim, H. N., Ibrahim, I., Jamil, A., Pandikumar, A. \& Huang, N. M. (2017). Horseradish peroxidase-labeled silver/reduced graphene oxide thin film-modified screen-printed electrode for detection of carcinoembryonic antigen. Biosensors and Bioelectronics, 89, 673-680.

[34] Bilgi, M., Sahin, E. M. \& Ayranci, E. (2018). Sensor and biosensor application of a new redox mediator: Rosmarinic acid modified screen-printed carbon electrode for electrochemical determination of NADH and ethanol. Journal of Electroanalytical Chemistry, 813, 67-74.

[35] Bilgi Kamac, M., Kiymaz Onat, E. \& Yilmaz, M. (2020). A novel non-enzymatic amperometric H2O2 sensor based on screen-printed electrode modified with reduced graphene oxide, polyneutralred and gold nanoparticles. International Journal of Environmental Analytical Chemistry, 100(4), 408-418.

[36] Yu, Z., Sun, S. \& Huang, M. (2016). Electrodeposition of gold nanoparticles on electrochemically reduced graphene oxide for high performance supercapacitor electrode materials. Int. J. Electrochem. Sci, 11(5), 3643-3650.

[37] Yang, R., Ruan, C., Dai, W., Deng, J. \& Kong, J. (1999). Electropolymerization of thionine in neutral aqueous media and $\mathrm{H} 2 \mathrm{O} 2$ biosensor based on poly (thionine). Electrochimica Acta, 44(10), 1585-1596.

[38] Karaboğa, M. N. S. \& Sezgintürk, M. K. (2019). Cerebrospinal fluid levels of alpha-synuclein measured using a poly-glutamic acid-modified gold nanoparticle-doped disposable neuro-biosensor system. Analyst, 144(2), 611-621.

[39] Yang, R., Ruan, C., Dai, W., Deng, J. \& Kong, J. (1999). Electropolymerization of thionine in neutral aqueous media and $\mathrm{H}_{2} \mathrm{O}_{2}$ biosensor based on poly (thionine). Electrochimica Acta, 44(10), 1585-1596.

[40] Gao, Q., Cui, X., Yang, F., Ma, Y. \& Yang, X. (2003). Preparation of poly (thionine) modified screenprinted carbon electrode and its application to determine NADH in flow injection analysis system. Biosensors and Bioelectronics, 19(3), 277-282.

[41] Feng, H., Wang, H., Zhang, Y., Yan, B., Shen, G. \& Yu, R. (2007). A direct electrochemical biosensing platform constructed by incorporating carbon nanotubes and gold nanoparticles onto redox poly (thionine) film. Analytical Sciences, 23(2), 235-239.

[42] Mai, N., Liu, X., Zeng, X., Xing, L., Wei, W. \& Luo, S. (2010). Electrocatalytic oxidation of the reduced nicotinamide adenine dinucleotide at carbon ionic liquid electrode modified with polythionine/multiwalled carbon nanotubes composite. Microchimica Acta, 168(3-4), 215-220. 
[43] Deng, C., Chen, J., Nie, Z., Yang, M. \& Si, S. (2012). Electrochemical detection of nitrite based on the polythionine/carbon nanotube modified electrode. Thin Solid Films, 520(23), 7026-7029.

[44] Sahin, M. \& Ayranci, E. (2015). Electrooxidation of NADH on modified screen-printed electrodes: effects of conducting polymer and nanomaterials. Electrochimica Acta, 166, 261-270.

[45] Qu, F., Yang, M., Chen, J., Shen, G. \& Yu, R. (2006). Amperometric Biosensors for Glucose Based on Layer-by-Layer Assembled Functionalized Carbon Nanotube and Poly (Neutral Red) Multilayer Film. Analytical Letters, 39(9), 1785-1799.

[46] Bard, A. J. \& Faulkner, L. R. (2001). Fundamentals and applications. Electrochemical Methods, 2(482), 580-632.

[47] Zhao, C., Jiang, Z., Cai, X., Lin, L., Lin, X. \& Weng, S. (2015). Ultrasensitive and reliable dopamine sensor based on polythionine/AuNPs composites. Journal of Electroanalytical Chemistry, 748, 16-22.

[48] Lai, G., Liu, Y., Yu, A., Han, D. \& Zhang, H. (2013). Simultaneous sensitive determination of dopamine and uric acid in the presence of excess ascorbic acid with a magnetic chitosan microsphere/thionine modified electrode. Analytical Letters, 46(10), 1525-1536.

[49] Liu, Y., Zhang, H. L., Lai, G. S., Yu, A. M., Huang, Y. M. \& Han, D. Y. (2010). Amperometric NADH biosensor based on magnetic chitosan microspheres/poly (thionine) modified glassy carbon electrode. Electroanalysis, 22(15), 1725-1732.

[50] Li, Z., Huang, Y., Chen, L., Qin, X., Huang, Z., Zhou, Y., Meng, Y., Li, J., Huang, S., Liu, Y., Wang, W., Xie, Q. \& Yao, S. (2013). Amperometric biosensor for NADH and ethanol based on electroreduced graphene oxide-polythionine nanocomposite film. Sensors and Actuators B: Chemical, 181, 280-287.

[51] Pruneanu, S., Biris, A. R., Pogacean, F., Socaci, C., Coros, M., Rosu, M. C., Watanabe, F. \& Biris, A. S. (2015). The influence of uric and ascorbic acid on the electrochemical detection of dopamine using graphene-modified electrodes. Electrochimica Acta, 154, 197-204.

[52] Chang, H., Wu, X., Wu, C., Chen, Y., Jiang, H. \& Wang, X. (2011). Catalytic oxidation and determination of $\beta$-NADH using self-assembly hybrid of gold nanoparticles and graphene. Analyst, 136(13), 2735-2740.

[53] Govindhan, M., Amiri, M. \& Chen, A. (2015). Au nanoparticle/graphene nanocomposite as a platform for the sensitive detection of NADH in human urine. Biosensors and Bioelectronics, 66, 474-480.

[54] Istrate, O. M., Rotariu, L., Marinescu, V. E. \& Bala, C. (2016). NADH sensing platform based on electrochemically generated reduced graphene oxide-gold nanoparticles composite stabilized with poly (allylamine hydrochloride). Sensors and Actuators B: Chemical, 223, 697-704.

[55] Immanuel, S. \& Sivasubramanian, R. (2020). Electrochemical studies of the oxidation of NADH on chemically reduced graphene oxide nanosheets modified glassy carbon electrode. Materials Chemistry and Physics, 123015.

[56] Devendiran, M., Kumar, K. K. \& Narayanan, S. S. (2018). Amperometric Determination of ascorbic acid and riboflavin using ferrocene/thionin bimediator modified electrode. Int JS Res Sci Technol, 4, 628-634.

[57] Szoke, A., Zsebe, Z., Turdean, G. L. \& Muresan, L. M. (2019). Composite Electrode Material Based on Electrochemically Reduced Graphene Oxide and Gold Nanoparticles for Electrocatalytic Detection of Ascorbic Acid. Electrocatalysis, 10(5), 573-583.

[58] Chethana, B. K. \& Naik, Y. A. (2012). Electrochemical oxidation and determination of ascorbic acid present in natural fruit juices using a methionine modified carbon paste electrode. Analytical Methods, 4(11), 3754-3759.

[59] Brett, C. M. A \& Brett, A. Maria Oliveira. (1993). Electrochemistry: principles, methods, and applications. Oxford: Oxford University Press.

[60] Harrison, J. A. \& Khan, Z. A. (1970). The oxidation of hydrazine on platinum in acid solution. Journal of Electroanalytical Chemistry and Interfacial Electrochemistry, 28(1), 131-138.

[61] Liu, B., Luo, L., Ding, Y., Si, X., Wei, Y., Ouyang, X. \& Xu, D. (2014). Differential pulse voltammetric determination of ascorbic acid in the presence of folic acid at electro-deposited $\mathrm{NiO} /$ graphene composite film modified electrode. Electrochimica Acta, 142, 336-342.

[62] Mie, Y., Yasutake, Y., Ikegami, M. \& Tamura, T. (2019). Anodized gold surface enables mediator-free and low-overpotential electrochemical oxidation of NADH: A facile method for the development of an NAD+-dependent enzyme biosensor. Sensors and Actuators B: Chemical, 288, 512-518.

[63] Fernández, L. \& Carrero, H. (2005). Electrochemical evaluation of ferrocene carboxylic acids confined on surfactant-clay modified glassy carbon electrodes: oxidation of ascorbic acid and uric acid. Electrochimica Acta, 50(5), 1233-1240. 
[64] Habibi, B., Jahanbakhshi, M., \& Pournaghi-Azar, M. H. (2011). Differential pulse voltammetric simultaneous determination of acetaminophen and ascorbic acid using single-walled carbon nanotubemodified carbon-ceramic electrode. Analytical Biochemistry, 411(2), 167-175. 